\title{
MULTIPLE ENDOTHELIAL CELLS CONSTITUTE THE TIP OF DEVELOPING BLOOD VESSELS AND POLARIZE TO PROMOTE LUMEN FORMATION
}

\author{
John Culver Pelton
}

A dissertation submitted to the faculty at the University of North Carolina at Chapel Hill in partial fulfillment of the requirements for the degree of Doctor of Philosophy in the Department of Biology.

Chapel Hill

2014

Approved by:

Victoria Bautch

Bob Goldstein

Alan Fanning

Ellie Tzima

Mark Peifer 
(c) 2014

John Culver Pelton

ALL RIGHTS RESERVED 


\section{ABSTRACT \\ John Culver Pelton: Multiple endothelial cells constitute the tip of developing blood vessels and polarize to promote lumen formation (Under the direction of Victoria Bautch)}

Blood vessel polarization in the apical-basal axis is important for directed secretion of proteins and lumen formation, yet when and how polarization occurs in the context of angiogenic sprouting is not well understood. The canonical model of angiogenic sprouts is a single cell, the tip cell, at the front of the sprout. I describe a novel topology for endothelial cells at the front of angiogenic sprouts in several mammalian vascular beds that disputes the classic tip cell model, and by using confocal and live imaging of mosaically-labeled endothelial cells I show that two cells significant overlap in space and time at the front of vessels, both in vitro and in vivo. The overlap is more extensive than predicted for tip cell switching, and it sets up a longitudinal cell-cell border that is apical polarization and lumen formation, presumably via a cord hollowing mechanism. The extent of cell overlap at the tip is reduced in mice lacking aPKC $\zeta$, and this is accompanied by reduced distal extension of both the apical border and patent lumens. Thus at least two cells occupy the tip of angiogenic sprouts for long periods of time, and apical-basal polarization that is influenced by aPKC $\zeta$ is close to the distal tips of blood vessel sprouts. 
I dedicate this work to Meghan 


\section{ACKNOWLEDGMENTS}

The many members of the Bautch lab have helped make this work possible. My lab mates have helped to create a great atmosphere to work in. They are friendly people who were willing to help me whenever I asked. I really appreciate all the work they have done to troubleshoot experiments, boost my confidence following set backs, and give sound advice on my project.

I have a helpful committee comprised of well-respected, accomplished scientists. Their insight and suggestions have helped to shape this project. This committee includes my advisor, Dr. Vicki Bautch. I thank her for all of her support and suggestions, and for allowing me to work a project that is interesting.

I would also like to thank my many friends outside of lab, some of which are science people and some not. They have helped me in many ways. They have helped edit my work, listened to experimental ideas, answered questions, and most importantly have helped keep me happy.

My wife, Meghan, has easily been the most helpful person in this project. It has been very helpful to have her be so knowledgeable about biology. She is always there to hear my ideas, and tell me why they don't make sense or how they could be better. She has read and edited most of the things I have written while in graduate school (including a large percentage of this document), and has made me 
a better writer. Her support and encouragement also helped me get through the experiments that didn't work. 


\section{TABLE OF CONTENTS}

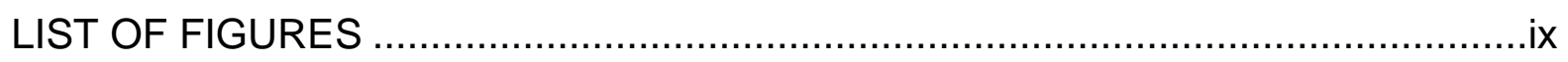

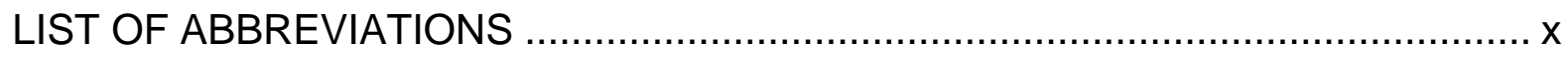

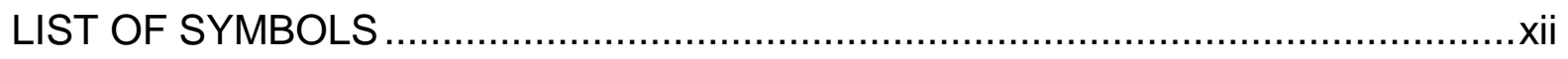

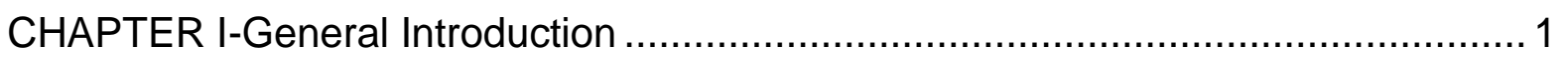

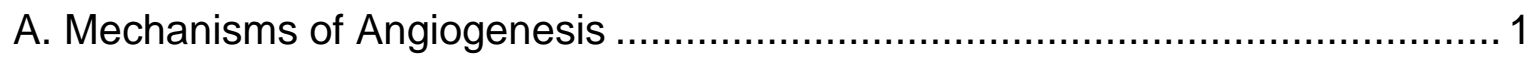

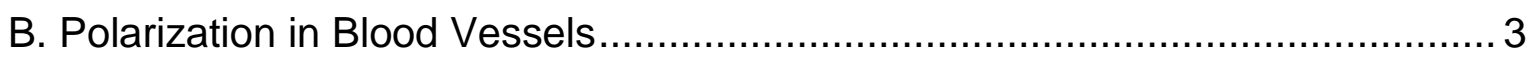

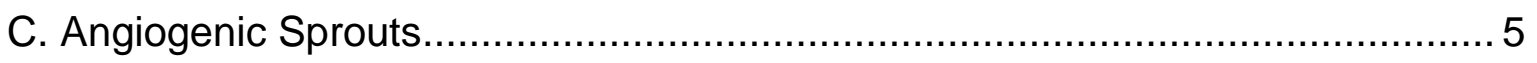

D. Atypical Protein Kinase C …........................................................... 7

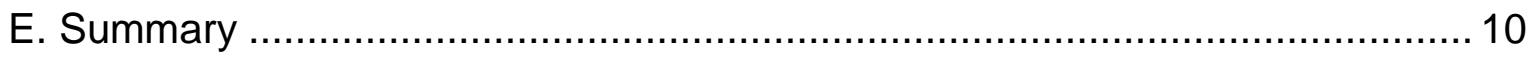

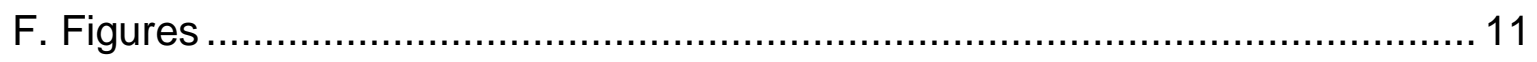

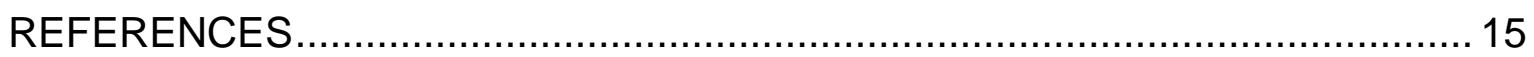

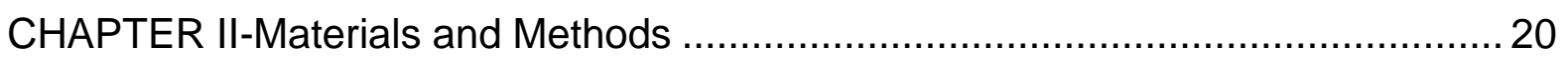

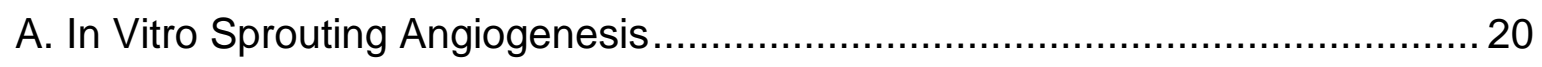

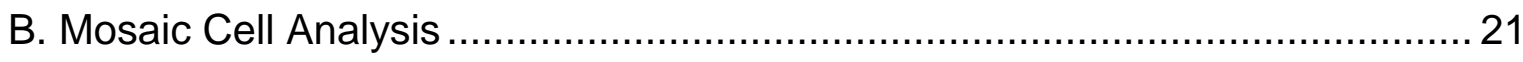

C. Mouse Retina and Embryonic Back Preparations...................................... 21

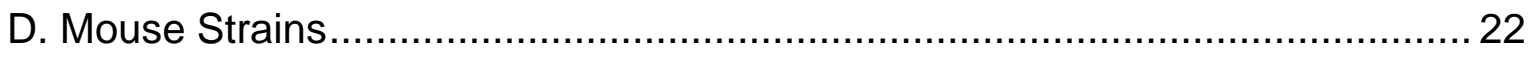

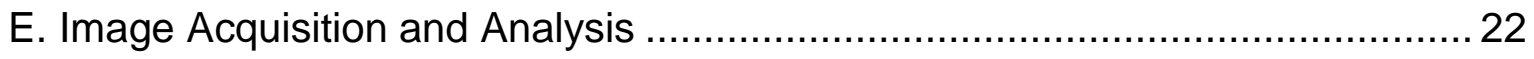

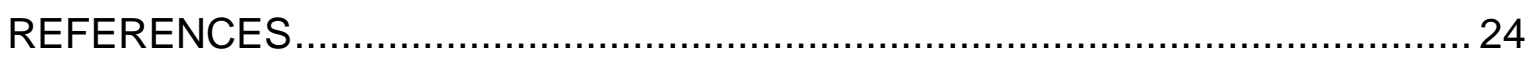

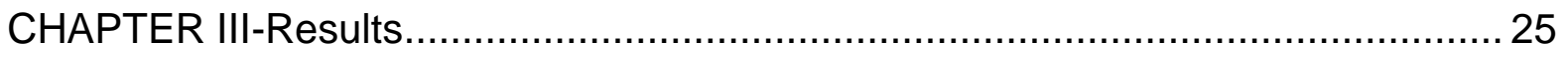




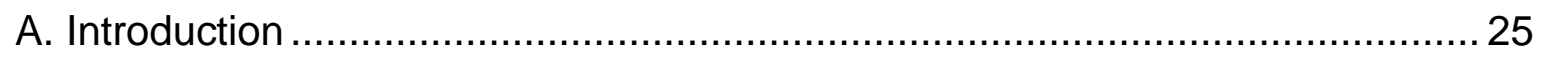

B. Sprout Tips are Composed of Two Overlapping Cells .................................. 28

C. Blood Vessel Sprouts Establish and Polarize along the Longitudinal Border between the Major and Minor Tip Cell ............................................................... 31

D. aPKC zeta knock down disrupts cell overlap leading to a defect in lumen

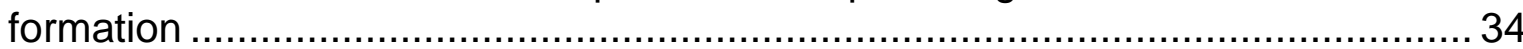

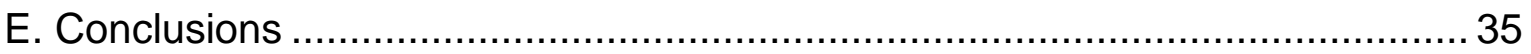

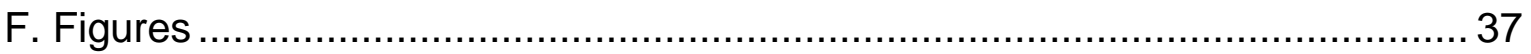

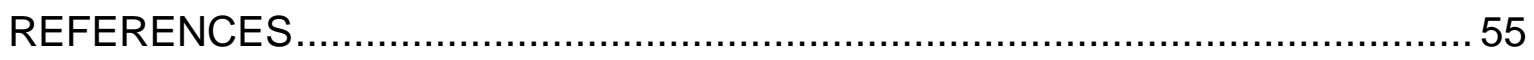

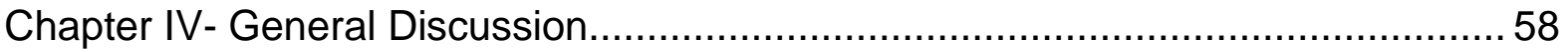

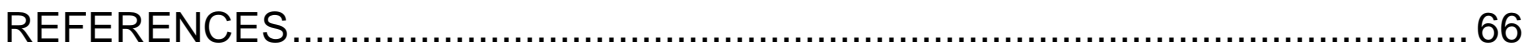




\section{LIST OF FIGURES}

Figure 1.1. Notch tip cell model ........................................................................... 11

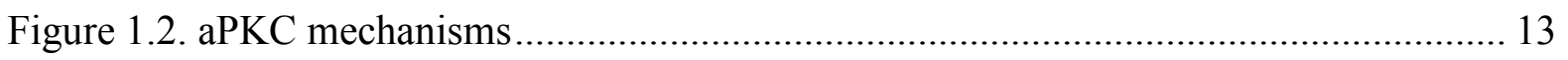

Figure 2.1. Multiple cells occupy the tip position in sprouts .......................................... 37

Figure 2.2. Multiple cells occupy the tip position in embryonic sprouts........................... 40

Figure 2.3. Endothelial cell dynamics lead to cell overlap in sprouts ............................... 42

Figure 2.4. Sprouts demonstrate apico-basal polarity in mature blood vessels ................... 44

Figure 2.5 Sprouts polarize at cell-cell border in sprout................................................. 46

Figure 2.6 Longitudinal border polarized ............................................................. 48

Figure 2.7 Sprouts have patent lumens formed between cells ..................................... 50

Figure 2.8 Loss of aPKC zeta perturbs cellular architecture in sprouts............................ 52

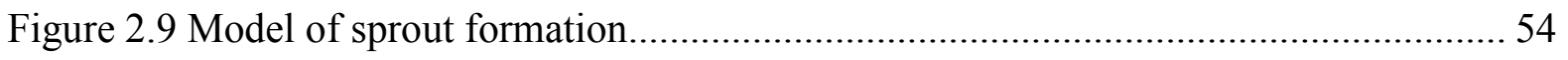




\section{LIST OF ABBREVIATIONS}

AJ - Adherens Junction

APC - adenomatous polyposis coli

aPKC $\zeta$ - atypical protein kinase $\zeta$

aPKC $\lambda$ - atypical protein kinase $\lambda$

BSA - Bovine Serum Albumin

Cdc42 - Cell division control protein 42 homolog

Coll IV- collagen IV

Cre-ER - Cre-Estrogren Receptor

Dab-2 - Disabled Homolog 2

DAPI - 4',6-diamidino-2-phenylindole

DII-4 - Delta like ligand 4

EBM-2 - Endothelium Basal Medium-2

eGFP - enhanced Green Fluorescent protein

FITC - Fluorescein isothiocyanate

Flk1 - Fetal liver kinase-1 (VEGFR-2)

Flt1 - fms-related tyrosine kinase 1 (VEGFR-1)

GFP - Green Fluorescent Protein

GSK-3ß- Glycogen synthase kinase 3 beta

hrs - Hours

HUVEC - Human Umbilical Vein Endothelial Cells

IB4 - Isolectin B4

Lgl - Lethal giant larvae 
Lgn - lateral geniculate nucleus

MDCK - Madin-Darby canine kidney

MTOC - Microtubule organizing center

Myt1 - myelin transcription factor 1

P5/P6 - Postnatal day 5/6

PBS - Phosphate Buffered Saline

Par3 - Partitioning defective 3

Par6 - Partitioning defective 6

PECAM - Platelet endothelial cell adhesion molecule

PFA - Paraformaldehyde

PODXL - podocalyxin

Rac1 - Ras-related C3 botulinum toxin substrate 1

RNA - Ribonucleic acid

s.e.m - Standard error about the mean

Tdtomato - tandem dimer tomato

VE-Cadherin - Vascular Endothelial Cadherin

VEGF - Vascular Endothelial Growth Factor

VEGFR-1 - Vascular Endothelial Growth Factor Receptor 1

VEGFR-2 - Vascular Endothelial Growth Factor Receptor 2

WT - Wild type

ZO1 - Zonula occludens protein 1 


\section{LIST OF SYMBOLS}

$$
\begin{aligned}
& \text { B - Beta } \\
& \zeta-\text { Zeta } \\
& \lambda-\text { Lambda } \\
& \mu-M u
\end{aligned}
$$




\section{CHAPTER I-General Introduction}

Embryonic growth, organ development, cancer progression and wound healing rely on the growth of new blood vessels (Chung \& Ferrara 2011, Nissen et al 1998, Risau 1997, Weis \& Cheresh 2011). These blood vessels are necessary for delivering oxygen, nutrients, and hormones throughout the body, and are required to take carbon dioxide and waste away from the organs and tissues of the body (Lammert \& Axnick 2012). Blood vessels lacking proper integrity cannot efficiently deliver or remove blood, leading to tissue death (Eltzschig \& Eckle 2011). Forming a proper vascular network is a complex process and requires many steps, including sprouting, polarization, lumenization, and migration (Lizama \& Zovein 2013, Risau 1997). This chapter will outline the molecular regulators of angiogenesis, focusing on the cellular topology and polarity of new sprouts.

\section{A. Mechanisms of Angiogenesis}

Descriptive work on circulation was published as early as the seventeenth century, observing that the heart pumps blood throughout the body, arteries take blood away from the heart, and veins return blood from the distant tissues (Harvey 1628). Subsequently, capillaries were identified as the intermediate vessels that link the arterial and venous systems within the tissues (Malpighi 1669). These initial observations established the framework for the modern field of vascular biology. Further research has described two processes that sequentially form the vascular network. The first is vasculogenesis, during which mesoderm-derived angioblasts 
differentiate into endothelial cells and coalesce to form a primitive vessel (Risau 1997). During the second process, angiogenesis, sprouts branch off a parent vessel to expand the vascular network, eventually migrating to connect with another sprout or vessel and form a new vascular path (Bussolino et al 1997).

In addition to the research done on physiological angiogenesis, the connection between angiogenesis and many disease states has been well documented (Chung \& Ferrara 2011, Nagy et al 2007). In 1939, pathological angiogenesis was shown in a rabbit tumor model, demonstrating that new blood vessels grow towards tumors (Ide 1939). In 1950, Algire et al. revealed that tumors induce new vessel formation more rapidly than angiogenesis occurs during wound healing, suggesting that tumors accelerate vascular growth (Algire et al 1950). Together, this data led Judah Folkman to propose that blocking angiogenesis might be an effective cancer treatment (Folkman 1971). In the years following, antiangiogenic treatments have been used in a wide variety of cancers and with moderate success (Shojaei 2012). For example, Bevacizumab, an anti-VEGF antibody created by Genentech, has successfully inhibited the growth of some cancers, including metastatic breast cancer (Folkman 1971, Miller et al 2007), metastatic colorectal cancer (Hurwitz et al 2004), and advanced clear-cell renal-cell carcinoma (Escudier et al 2007). Unfortunately these treatments have not achieved the success that was initially predicted. Blocking angiogenesis leads to a temporary increase in progression-free survival, as patients respond to anti-angiogenesis treatments initially, but become resistant to anti-angiogenesis treatments over time (Ahluwalia \& Gladson 2010, Verhoeff et al 2009). The same anti-angiogenesis 
treatments have also been shown to increase metastasis of tumors, which may explain why these treatments have not increased overall patient survival (Saidi et al 2008). These results show the potential power in targeting cancer angiogenesis while highlighting the need for a better understanding of the mechanisms underlying angiogenesis.

\section{B. Polarization in Blood Vessels}

As the vascular network forms, blood vessels must polarize, establishing an apical side that surrounds the lumen and interacts with the blood, and a basal surface that interacts with surrounding cells and matrixes. The first analysis of apical-basal polarity in blood vessels was conducted nearly thirty years ago, showing immuno-gold labeling of podocalyxin only at the apical surface of capillaries (Horvat et al 1986). Recent work on apical-basal polarity in vascular biology has largely studied vasculogenic processes using in vitro assays and the mouse aorta, ignoring angiogenesis (Bryant et al 2010, Koh et al 2008, Lampugnani et al 2010). Because of this, understanding where, when and how polarity is established in angiogenesis remains limited.

Blood vessels must polarize in the apical-basal axis to form a lumen, and the majority of work done in angiogenic polarity has focused on polarity as a prerequisite for lumen formation. Many mechanisms for tube formation have been identified (reviewed in Lubarsky \& Krasnow 2003). During blood vessel formation, two tubeformation mechanisms, cell hollowing and cord hollowing, have been proposed and it remains an issue of debate as to which is the dominant mechanism (Lammert \& Axnick 2012). Cell hollowing is a process of intracellular lumen formation single 
cells vesicles and vacuoles towards the center of the cell. These vesicles and vacuoles fuse with one another to form an intracellular lumen that is further connected to lumens in adjacent cells (Lubarsky \& Krasnow 2003). In contrast, the cord hollowing mechanism suggests that a lumen forms between two adjacent cells (Lubarsky \& Krasnow 2003). Initially, cell hollowing was assumed to be the mechanism for tube formation during angiogenesis, as endothelial cells grown in collagen matrix were observed to form intracellular lumens. (Folkman \& Haudenschild 1980, Kamei et al 2006). Additionally, zebrafish intersegmental vessels were thought to form lumens via cell hollowing, suggesting that cell hollowing was the mechanism for tube formation during angiogenesis in vivo (Kamei et al 2006). More recent work, however, has called these early studies into question. Detailed analysis of the junctional marker, zonula occludens-1 (ZO1), and single cell imaging in the zebrafish intersegmental vessels suggested that the intersegmental vessels have complex overlapping cellular positions, not a stacked formation as was previously thought, thus lumens may actually form between cells (Herwig et al 2011) . Further supporting the cord hollowing model, MDCK cysts, an in vitro epithelial model that frequently parallels blood vessel formation, form lumens between two cells (Bryant et al 2010). Additionally, the mouse aorta lumenizes using a cord-hollowing mechanism (Strilic et al 2009). Although the mouse aorta is formed through vasculogenesis, it is likely that blood vessels formed via angiogenesis use a similar mechanism.

The molecular mechanisms governing lumen formation identified in other contexts are excellent candidates for regulating lumen formation during 
angiogenesis. The Mostov lab discovered that in MDCK cysts Rab11a controls the apical trafficking of Par-3, podocalyxin, and TUBA, and the apical trafficking of these proteins is required to establish the apical domain of epithelial cells and for lumen formation (Bryant et al 2010). It is reasonable to hypothesize that blood vessel polarization may occur through an analogous process. Additionally, loss of Cdc42 and Rac1 lead to a loss of lumen formation in epithelial in vitro models (Koh et al 2008). Cdc42 and Rac1 are important in developmental and pathological contexts, including polarized cellular migration (Etienne-Manneville 2004, Ferri et al 2013, Stengel \& Zheng 2011). In the mouse retina vasculature, loss of basally localized, $\beta 1$ integrin causes a loss of lumen formation and correlates with lower levels of the polarity protein Par-3 present in endothelial cells (Zovein et al 2010). Together, these studies identify many potential regulators of both polarity and lumen formation during angiogenesis.

Despite extensive investigation of polarization and tube formation in other contexts, how apical-basal polarity is established during sprouting angiogenesis remains unclear. Establishing apical-basal polarity is necessary for proper developmental angiogenesis as described above, and may play a role in pathological angiogenesis. Interestingly, tumor induced blood vessels are known to be leaky, mis-patterned, and lacking proper adhesion, which could be the result of improper polarization or could lead to polarization defects. Elucidating how apicalbasal polarity is established in developing sprouts will enhance our understanding of angiogenesis in both physiological and disease states.

\section{Angiogenic Sprouts}


Blood vessels begin to form a lumen near the tip of a new angiogenic sprout, suggesting that new sprouts quickly establish apical-basal polarity (Gerhardt et al 2003). Because of this, understanding the cellular topology of new sprouts is a crucial aspect of understanding how polarity is established. To initiate angiogenesis, endothelial cells sprout preexisting vessels and migrate away from the parent vessel while maintaining cell-cell connections, expanding an existing network (Horowitz \& Simons 2008). Traditionally, a single migratory cell, termed the tip cell, was thought to lead the sprout away from the parent vessel (see Fig 1.1). Tip cells appear to be migratory cells with filopodia extending in the direction of growth (Gerhardt et al 2003). The tip cell dampens the migratory properties of the surrounding stalk cells using Notch lateral inhibition (Hellstrom et al 2007). Molecularly, this cascade is initiated when vascular endothelial growth factor-A (VEGF-A) binds to the VEGF receptor 2 (VEGFR2/FIk1) within the tip cell. The tip cell, as the most distal cell, is exposed to the highest levels of VEGF-A (Gerhardt et al 2003). Binding of VEGF-A triggers a signaling cascade causing the tip cell to initiate a migratory phenotype and increase production of the membrane bound Notch ligand delta-like 4 (DII4) (Hellstrom et al 2007). DIl4 binds Notch on the neighboring stalk cells, where the Notch receptor is cleaved and localizes to the nucleus. This activates transcription of Hes and Hey family genes, leading to down-regulated VEGFR2 and up-regulated VEGF receptor-1 (VEGFR1/FIt1) (Harrington et al 2008, Iso et al 2003). VEGFR1 binds VEGF ligand and acts as a ligand sink, thereby dampening the response to VEGF signaling in the stalk cells (Chappell et al 2009). Transcriptome analysis of DII4+/- mice demonstrated that extracellular matrix degrading enzymes, secreted 
proteins, and basement membrane components were enriched in endothelial cells from mouse retina vasculature in DII $4+/$ - mice, suggesting that these protein groups were enriched in tip cells (del Toro et al 2010). These studies demonstrate heterogeneity in sprouts and have reinforced the idea that there is a single tip cell in angiogenic sprouts.

In contrast to the original work suggesting a static tip cell fate reinforced through Notch signaling, recent publications have suggested that tip cell fate may be dynamic (Arima et al 2011, Jakobsson et al 2010). This in vitro work has shown that a stalk cell overtakes the tip cell and becomes a new tip cell once every 4-7 hours, as measured by nuclear position over time. This has led to a sprouting model where a single cell leads a sprout until a switching event occurs, at which point a new tip cell is created that then leads the sprout. Such a model implies that a single stalk cell overlaps the tip cell during the switching event, but that the traditional stacked topology is present during the remainder of the sprouting process. However, as this model was formed from measurements of the nuclear position and not the positioning of the cell body, these experiments fall short of revealing the true topology of sprouts. Nuclear measurements fail to take into account the shape of the endothelial cells, which extend an average of five times further than the cell nucleus (Adamson 1993, Kang et al 2011). This work has begun to challenge the single tip cell model, but fails to fully understand the topology of the angiogenic sprout.

\section{Atypical Protein Kinase C}

The molecular processes that establish apical-basal polarity in the endothelial cells of blood vessels are poorly understood. However, a large body of research on 
polarity in other cell and tissue types has provided strong candidates for regulating apical-basal polarity. Atypical protein kinase $\mathrm{C}(\mathrm{aPKC})$ is necessary for polarity in multiple contexts, such as polarity in neuroblasts, lumen formation in epithelial tissues, and cell migration in migrating epithelial cells (Bryant et al 2010, Nishimura \& Kaibuchi 2007, Rolls et al 2003). There are two mammalian aPKCs, aPKC $\lambda$ and

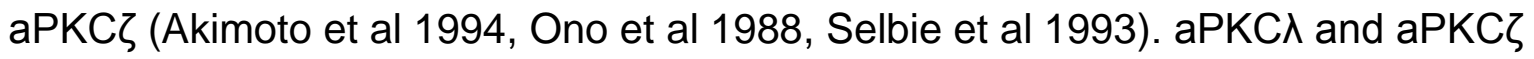
have $72 \%$ amino acid identity, and conservation is higher in functional domains such as the kinase domain (86\% conservation) (Akimoto et al 1994). aPKC binds to Par6 through its PB1 domain (Noda et al 2003). The canonical aPKC-Par-6 complex can receive upstream input from Cdc42 and Rac1, which bind to Par-6 when activated (Lin et al 2000). This binding causes the activation of aPKC and leads to the establishment of polarity (Henrique \& Schweisguth 2003).

Previous aPKC studies have suggested many mechanisms through which aPKC may regulate angiogenesis. First, aPKC may regulate oriented cell division, as has been observed in epithelial cysts. Oriented cell division in epithelial cysts relies on aPKC phosphorylating LGN, a linker protein used to connect the astral microtubules and thereby anchor the spindle pole to the cortex (Zheng et al 2010). After phosphorylation by aPKC, LGN is excluded from the apical surface, causing the mitotic spindle to orient perpendicularly to the apical-basal axis. Alternatively, aPKC may facilitate proper angiogenesis by affecting directed cell migration. One way that aPKC is known to affect cell migration through inactivation of glycogen synthase kinase 3 (GSK-3ß). This allows adenomatous polyposis coli (APC) to stabilize microtubule plus-ends at the leading edge, promoting migration towards 
that edge. Additionally, aPKC could regulate cell-cell junctions during angiogenesis through its interaction with Par-3, which must be phosphorylated at ser-827 for the establishment of proper tight junctions (Hirose 2002). Finally, aPKC could be necessary for establishing and maintaining the apical domain through its antagonistic relationship with lethal giant larvae $(\mathrm{Lgl})$, a protein required for basolateral domain in epithelial cells (Chalmers et al 2005). aPKC phosphorylation of Lgl prevents its cortical localization and therefore removes Lgl from the apical membrane where aPKC is localized (Chalmers et al 2005). These mechanisms all affect polarization in different contexts and could be potential mechanisms for maintaining proper polarization in the blood vessel.

Importantly, current research suggests that aPKC is necessary for angiogenesis. Endothelial cells grown in a collagen matrix will lumenize, and disrupting aPKC with an aPKC pseudosubstrate inhibitor blocks this process (Koh et al 2008). Additionally, in vivo mouse work has shown that aPKC $\lambda$ is necessary for proper down regulation of VEGF signaling (Nakayama et al 2013). Vascular specific knock-out of aPKC $\lambda$ led to increased proliferation, sprouting, filopodia, and branching in the mouse retina vasculature, specifically increased behind the vascular front (Nakayama et al 2013). Activation of VEGF-VEGFR2 signaling is coincident with Dab-2-dependent internalization of VEGFR2 at the vascular front of the mouse retina vasculature, a process regulated by aPKC $\lambda$ (Nakayama et al 2013). Interestingly, aPKC $\lambda$ is active only behind the vascular front and spatially regulates VEGFR2 internalization through an inhibitory phosphorylation of Dab-2 in endothelial cells behind the vascular front (Nakayama et al 2013). These data suggest a 
function for aPKC in the vasculature outside of polarization. The work done by Nakayama et al does not investigate the role of aPKC $\zeta$, and therefore does not elucidate its possible role in polarization or any possible redundancy between the two proteins.

\section{E. Summary}

Blood vessel formation has been studied for many years, highlighting its importance in developmental and pathological processes. Despite studies looking at polarization and lumen formation, both the establishment of apical basal polarity and the mechanism of lumen formation remain unknown. The roles of VEGF and Notch signaling pathways have been extensively studied in new angiogenic sprouts, yet the cellular topology of these sprouts remains understudied. The understanding of these pathways will help elucidate how angiogenesis occurs, and will establish the background for the study of angiogenesis in physiological and pathological angiogenesis. 


\section{F. Figures}

Figure 1.1. Notch tip cell model. Model illustrating the classic tip cell model in sprouting angiogenesis. A single tip cell (light green) leads the stalk cells (dark green). The tip cell expresses the notch ligand, DII4. This binds with the Notch receptor on the stalk cells, which triggers the inhibition of VEGFR2 production and an increase in VEGFR1. This process dampens the stalk cells response to VEGF. 


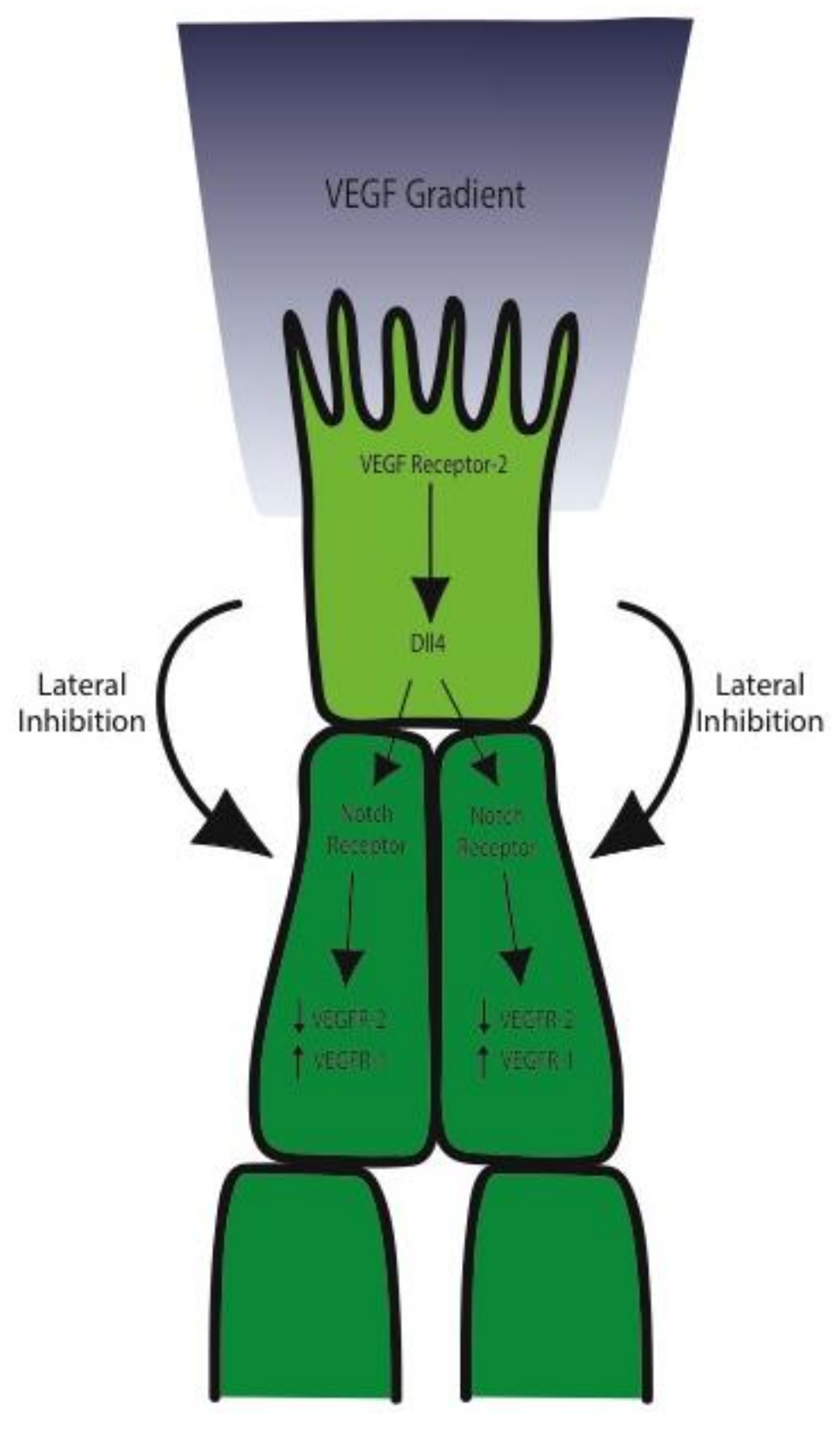


Figure 1.2. aPKC mechanisms. Model depicting mechanisms of aPKC pathways that have affects on polarity and or cell migration. aPKC inhibits Gsk-3 $\beta$ through phosphorylation, APC to stabilize microtubules and promote directed cell migration. aPKC also phosphorylates LGN, which dictates directed cell division. In addition, aPKC helps set up the basal lateral domain, through its antagonism of Lgl via phosphorylation. aPKC binds Par3 and helps to establish tight junction formation. 
Microtubule Stabalization and

Cell Migration

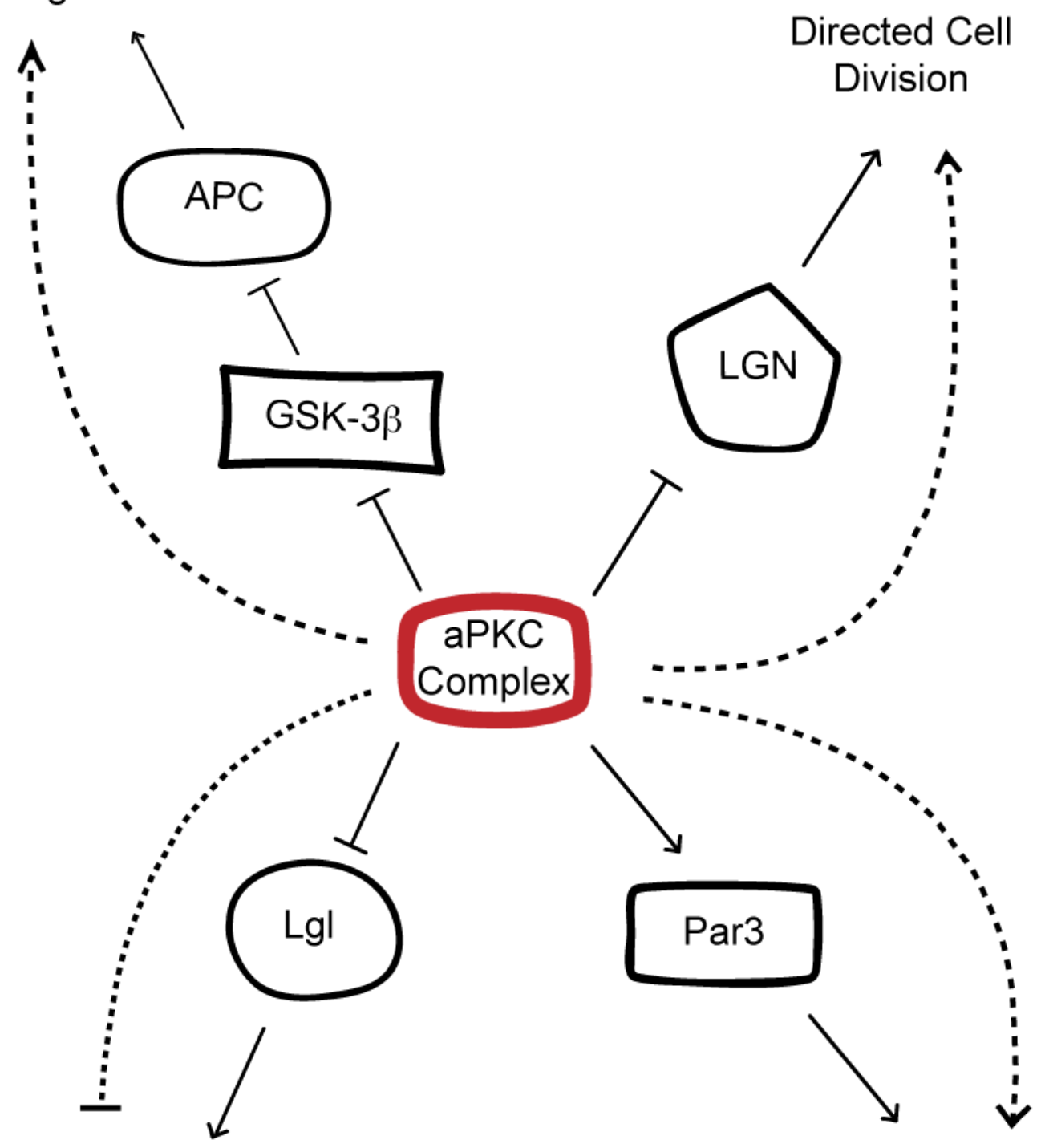

Basal-lateral Domain

Tight Junciton

Establsihment

Formation 


\section{REFERENCES}

Adamson RH. 1993. Microvascular endothelial cell shape and size in situ. Microvascular research 46: 77-88

Ahluwalia MS, Gladson CL. 2010. Progress on antiangiogenic therapy for patients with malignant glioma. Journal of oncology 2010: 689018

Akimoto K, Mizuno K, Osada S, Hirai S, Tanuma S, et al. 1994. A new member of the third class in the protein kinase $\mathrm{C}$ family, PKC lambda, expressed dominantly in an undifferentiated mouse embryonal carcinoma cell line and also in many tissues and cells. The Journal of biological chemistry 269: 12677-83

Algire GH, Chalkley HW, Earle WE, Legallais FY, Park HD, et al. 1950. Vascular reactions of normal and malignant tissues in vivo. III. Vascular reactions' of mice to fibroblasts treated in vitro with methylcholanthrene. Journal of the National Cancer Institute 11: 555-80

Arima S, Nishiyama K, Ko T, Arima Y, Hakozaki Y, et al. 2011. Angiogenic morphogenesis driven by dynamic and heterogeneous collective endothelial cell movement. Development 138: 4763-76

Bryant DM, Datta A, Rodriguez-Fraticelli AE, Peranen J, Martin-Belmonte F, Mostov KE. 2010. A molecular network for de novo generation of the apical surface and lumen. Nature cell biology 12: 1035-45

Bussolino F, Mantovani A, Persico G. 1997. Molecular mechanisms of blood vessel formation. Trends in biochemical sciences 22: 251-6

Chalmers AD, Pambos M, Mason J, Lang S, Wylie C, Papalopulu N. 2005. aPKC, Crumbs3 and Lgl2 control apicobasal polarity in early vertebrate development. Development 132: 977-86

Chappell JC, Taylor SM, Ferrara N, Bautch VL. 2009. Local guidance of emerging vessel sprouts requires soluble Flt-1. Developmental cell 17: 377-86

Chung AS, Ferrara N. 2011. Developmental and pathological angiogenesis. Annual review of cell and developmental biology 27: 563-84

del Toro R, Prahst C, Mathivet T, Siegfried G, Kaminker JS, et al. 2010. Identification and functional analysis of endothelial tip cell-enriched genes. Blood 116: 4025-33

Eltzschig HK, Eckle T. 2011. Ischemia and reperfusion--from mechanism to translation. Nature medicine 17: 1391-401 
Escudier B, Eisen T, Stadler WM, Szczylik C, Oudard S, et al. 2007. Sorafenib in advanced clear-cell renal-cell carcinoma. The New England journal of medicine 356: 125-34

Etienne-Manneville S. 2004. Cdc42--the centre of polarity. Journal of cell science 117: 1291-300

Ferri N, Contini A, Bernini SK, Corsini A. 2013. Role of small GTPase protein Rac1 in cardiovascular diseases: development of new selective pharmacological inhibitors. Journal of cardiovascular pharmacology 62: 425-35

Folkman J. 1971. Tumor angiogenesis: therapeutic implications. The New England journal of medicine 285: 1182-6

Folkman J, Haudenschild C. 1980. Angiogenesis in vitro. Nature 288: 551-6

Gerhardt H, Golding M, Fruttiger M, Ruhrberg C, Lundkvist A, et al. 2003. VEGF guides angiogenic sprouting utilizing endothelial tip cell filopodia. The Journal of cell biology 161: 1163-77

Harrington LS, Sainson RC, Williams CK, Taylor JM, Shi W, et al. 2008. Regulation of multiple angiogenic pathways by Dll4 and Notch in human umbilical vein endothelial cells. Microvascular research 75: 144-54

Harvey W. 1628. Exercitatio Anatomica de Motu Cordis et Sanguinis.

Hellstrom M, Phng LK, Hofmann JJ, Wallgard E, Coultas L, et al. 2007. Dll4 signalling through Notch1 regulates formation of tip cells during angiogenesis. Nature 445: 776-80

Henrique D, Schweisguth F. 2003. Cell polarity: the ups and downs of the Par6/aPKC complex. Current opinion in genetics \& development 13: 341-50

Herwig L, Blum Y, Krudewig A, Ellertsdottir E, Lenard A, et al. 2011. Distinct cellular mechanisms of blood vessel fusion in the zebrafish embryo. Current biology : $C B$ 21: $1942-8$

Horowitz A, Simons M. 2008. Branching morphogenesis. Circulation research 103: 78495

Horvat R, Hovorka A, Dekan G, Poczewski H, Kerjaschki D. 1986. Endothelial cell membranes contain podocalyxin--the major sialoprotein of visceral glomerular epithelial cells. The Journal of cell biology 102: 484-91

Hurwitz H, Fehrenbacher L, Novotny W, Cartwright T, Hainsworth J, et al. 2004. Bevacizumab plus irinotecan, fluorouracil, and leucovorin for metastatic colorectal cancer. The New England journal of medicine 350: 2335-42 
Ide AG, Baker, N.H. \& Warren, S.L. 1939. Vascularization of the Brown Pearce rabbit epithelioma transplant as seen in the transparent ear chamber. Am. J. Roentgenol 42: 891-99

Iso T, Kedes L, Hamamori Y. 2003. HES and HERP families: multiple effectors of the Notch signaling pathway. Journal of cellular physiology 194: 237-55

Jakobsson L, Franco CA, Bentley K, Collins RT, Ponsioen B, et al. 2010. Endothelial cells dynamically compete for the tip cell position during angiogenic sprouting. Nature cell biology 12: 943-53

Kamei M, Saunders WB, Bayless KJ, Dye L, Davis GE, Weinstein BM. 2006. Endothelial tubes assemble from intracellular vacuoles in vivo. Nature 442: 453-6

Kang MH, Balaratnasingam C, Yu PK, Morgan WH, McAllister IL, et al. 2011. Morphometric characteristics of central retinal artery and vein endothelium in the normal human optic nerve head. Investigative ophthalmology \& visual science 52: $1359-67$

Koh W, Mahan RD, Davis GE. 2008. Cdc42- and Rac1-mediated endothelial lumen formation requires Pak2, Pak4 and Par3, and PKC-dependent signaling. Journal of cell science 121: 989-1001

Lammert E, Axnick J. 2012. Vascular lumen formation. Cold Spring Harbor perspectives in medicine 2: a006619

Lampugnani MG, Orsenigo F, Rudini N, Maddaluno L, Boulday G, et al. 2010. CCM1 regulates vascular-lumen organization by inducing endothelial polarity. Journal of cell science 123: 1073-80

Lin D, Edwards AS, Fawcett JP, Mbamalu G, Scott JD, Pawson T. 2000. A mammalian PAR-3-PAR-6 complex implicated in Cdc42/Rac1 and aPKC signalling and cell polarity. Nature cell biology 2: 540-7

Lizama CO, Zovein AC. 2013. Polarizing pathways: balancing endothelial polarity, permeability, and lumen formation. Experimental cell research 319: 1247-54

Lubarsky B, Krasnow MA. 2003. Tube morphogenesis: making and shaping biological tubes. Cell 112: 19-28

Malpighi M. 1669. De viscerum structura exercitatio anatomica. Amstelodami: Apud Petrum Le Grand. 12,168 p. pp. 
Miller K, Wang M, Gralow J, Dickler M, Cobleigh M, et al. 2007. Paclitaxel plus bevacizumab versus paclitaxel alone for metastatic breast cancer. The New England journal of medicine 357: 2666-76

Nagy JA, Dvorak AM, Dvorak HF. 2007. VEGF-A and the induction of pathological angiogenesis. Annual review of pathology 2: 251-75

Nakayama M, Nakayama A, van Lessen M, Yamamoto H, Hoffmann S, et al. 2013. Spatial regulation of VEGF receptor endocytosis in angiogenesis. Nature cell biology 15: $249-60$

Nishimura T, Kaibuchi K. 2007. Numb controls integrin endocytosis for directional cell migration with aPKC and PAR-3. Developmental cell 13: 15-28

Nissen NN, Polverini PJ, Koch AE, Volin MV, Gamelli RL, DiPietro LA. 1998. Vascular endothelial growth factor mediates angiogenic activity during the proliferative phase of wound healing. The American journal of pathology 152: 1445-52

Noda Y, Kohjima M, Izaki T, Ota K, Yoshinaga S, et al. 2003. Molecular recognition in dimerization between PB1 domains. The Journal of biological chemistry 278: 43516-24

Ono Y, Fujii T, Ogita K, Kikkawa U, Igarashi K, Nishizuka Y. 1988. The structure, expression, and properties of additional members of the protein kinase $\mathrm{C}$ family. The Journal of biological chemistry 263: 6927-32

Risau W. 1997. Mechanisms of angiogenesis. Nature 386: 671-4

Rolls MM, Albertson R, Shih HP, Lee CY, Doe CQ. 2003. Drosophila aPKC regulates cell polarity and cell proliferation in neuroblasts and epithelia. The Journal of cell biology 163: 1089-98

Saidi A, Javerzat S, Bellahcene A, De Vos J, Bello L, et al. 2008. Experimental antiangiogenesis causes upregulation of genes associated with poor survival in glioblastoma. International journal of cancer. Journal international du cancer 122: 2187-98

Selbie LA, Schmitz-Peiffer C, Sheng Y, Biden TJ. 1993. Molecular cloning and characterization of PKC iota, an atypical isoform of protein kinase $\mathrm{C}$ derived from insulin-secreting cells. The Journal of biological chemistry 268: 24296-302

Shojaei F. 2012. Anti-angiogenesis therapy in cancer: current challenges and future perspectives. Cancer letters 320: 130-7

Stengel K, Zheng Y. 2011. Cdc42 in oncogenic transformation, invasion, and tumorigenesis. Cellular signalling 23: 1415-23 
Strilic B, Kucera T, Eglinger J, Hughes MR, McNagny KM, et al. 2009. The molecular basis of vascular lumen formation in the developing mouse aorta. Developmental cell 17: $505-15$

Verhoeff JJ, van Tellingen 0, Claes A, Stalpers LJ, van Linde ME, et al. 2009. Concerns about anti-angiogenic treatment in patients with glioblastoma multiforme. $B M C$ cancer 9: 444

Weis SM, Cheresh DA. 2011. Tumor angiogenesis: molecular pathways and therapeutic targets. Nature medicine 17: 1359-70

Zheng Z, Zhu H, Wan Q, Liu J, Xiao Z, Siderovski DP, Du Q. LGN regulates mitotic spindle orientation durhing epithelial morphogenesis. Journal of Cell Biology 275-288

Zovein AC, Luque A, Turlo KA, Hofmann JJ, Yee KM, et al. 2010. Beta1 integrin establishes endothelial cell polarity and arteriolar lumen formation via a Par3dependent mechanism. Developmental cell 18: 39-51 


\section{CHAPTER II-Materials and Methods}

\section{A. In Vitro Sprouting Angiogenesis}

Human umbilical vein endothelial cells (HUVEC) were cultured as described (Nakatsu et al 2007). Briefly, HUVEC were incubated for $4 \mathrm{hr}$ with Cytodex-3 microcarrier beads (Amersham Pharmacia Biotech) in EBM-2 media supplemented with an EGM-2 Bullet Kit (Lonza). The next day the beads were washed and suspended in PBS with $2 \mathrm{mg} / \mathrm{ml}$ Fibrinogen (MP Biomedicals) and $0.15 \mathrm{U} / \mathrm{ml}$ aprotinin (Sigma). A total volume of $1 \mathrm{ml}$ of the suspension was plated on $35 \mathrm{~mm}$ glass bottom plates with $0.625 \mathrm{U} / \mathrm{ml}$ of thrombin (Sigma). Plates were grown for 6-8 days before being fixed with 2\% PFA. After washing plates, cells were permeabilized with $.5 \%$ Triton-X for 2 hours. Cells are then blocked overnight at $4^{\circ}$ Celsius with $1 \%$

goat serum and 1\%BSA. Cells were stained with anti-human PECAM conjugated to Alexa Fluor 488 (Invitrogen) at 1:100, goat anti-human podocalyxin (R\&D systems) at 1:100, rabbit anti-human collagen IV (AbD Serotec) at 1:100, and mouse antihuman $\beta 1$ integrin (Abcam) at 1:100. Secondary antibodies used at 1:200 were donkey anti-goat 546 Alexa Fluor (Invitrogen), and donkey anti-rabbit 647 Alexa Fluor (Invitrogen).

For mosaic experiments, HUVEC were infected with lentivirus 2-3 days prior to the assay. The viral plasmids, containing either cytoplasmic eGFP or cytoplasmic tdTomato (Rompani \& Cepko 2008), were incubated with HUVEC for 16-20 hr in 2 $\mu \mathrm{g} / \mathrm{mL}$ polybrene in supplemented EMB-2 media. 


\section{B. Mosaic Cell Analysis}

Sprouts were counted in vitro if the two most distal cells were different colors, regardless of overlap. In the retina and embryonic back, sprouts were counted if one of the two most distal cells expressed the tomato reporter and the other most distal cell was negative for the tomato reporter, but positive for IB4. The length of the leading cell was measured from the proximal side of the nucleus to the most distal end of the sprout. Overlap of the coincident cells was calculated as the percentage of the leading cell length that overlapped with the second leading cell.

\section{Mouse Retina and Embryonic Back Preparations}

Retinas were fixed, processed, and stained with isolectin GS-IB4 conjugated to Alexa Fluor 647 (Molecular Probes) as previously described (Gerhardt et al 2003). Briefly, P5-P6 mice were anesthetized with isoflurane and perfused with 0.5\% PFA in PBS. Eyes were fixed in 2\% PFA for $2 \mathrm{hr}$ at room temperature. Retinas were dissected and stained with 1:200 isolectin GS-IB4 overnight at $4^{\circ}$ Celsius. Retinas were further stained overnight at $4^{\circ}$ Celsius using goat anti-mouse podocalyxin (R\&D systems) at 1:50, rabbit anti-mouse collagen IV (AbD serotec) at 1:200, or rat anti-mouse $\beta 1$ integrin (BD Pharmigen) at 1:50. Secondary antibodies used were Alexa Fluors (Invitrogen) Donkey anti-goat 594, donkey anti-mouse 546, donkey anti-rabbit 647, donkey anti-rabbit 594, and donkey anti-rat 488 .

Dextran perfusion labeling was done as described by (Gerhardt et al 2003). Briefly, $20 \mathrm{mg} / \mathrm{ml}$ Fluorescein isothiocyanate-dextran (Sigma-FD2000S) was suspended in $0.5 \%$ PFA in PBS and was injected into isoflurane (Baxter) anesthetized P5-P6 pups. Embryos were fixed in 4\% PFA overnight at 4 degrees 
Celsius. Mouse embryo backs were dissected in PBS, dorsal to the somites and cranially from the cervical vertebrae through the caudal tail vertebrae. Samples were blocked at 4 degrees Celsius in PBS with 1\% triton-X (Invitrogen) and 3\% goat serum (Sigma-Aldrich) overnight. Back samples were washed 3 times at room temperature for 5 minutes in PBS. Skin samples were then incubated in rat antimouse PECAM (BD Pharmingen) at 1:100 overnight at 4 degrees Celsius. Samples were then washed in PBS 4 times for 45 minutes. Samples were then incubated with goat anti-rat Alexa 488 (Invitrogen) at 1:500 overnight at 4 degrees Celsius. Skin samples were flattened and mounted in Fluoromount (Southern Biotech), beneath glass coverslips (Fisher Scientific).

\section{Mouse Strains}

A ubiquitous Cre-ER mouse line, UBC-Cre/ESR1 (Ruzankina et al 2007), was mated with an R26R tomato Cre-dependent mouse line (Monvoisin et al 2006). Tamoxifen was injected at a dose of $.25 \mathrm{mg} \mathrm{ml}^{-1}$ in 9:1 sunflower seed oil to EtOH. aPKC $\zeta$ genetic deletion mice (Leitges et al 2001) were compared to wildtype littermate controls for nuclei overlap, patent lumen analysis, and polarization measurements. VE-Cadherin Cre/+;R26R tomato/R26R tomato mice were used in the analysis of embryonic back mosaic vessels.

\section{E. Image Acquisition and Analysis}

Fixed images were taken using a Leica DMI 6000B confocal microscope. Zstacks were deconvolved using Huygens Essential v. 3.5. Line plots of immunostained cells were generated using Huygens Essential software. Line scans were measured either starting inside the lumen to outside the vessel (Fig 2.4), or 
across a single membrane within the sprout (Fig 2.6). A minimum of 3 line scans per sprout/cell were averaged together, and a minimum of 10 sprouts/cells were used per experiment from at least 3 different mice. Apical and basal membranes were determined in orthogonal views using line plot analysis of isolectin that extended from the lumen to the vessel exterior. Line plot values were then measured for polarity markers on the same line. Values were internally compared between the apical and basal membranes. Pixel intensity was taken as a ratio of the membrane marker isolectin. To determine polarization of lateral and longitudinal cell-cell borders, line plots of polarity markers were measured across lateral and longitudinal borders. Cell-cell border intensity ratios were comprised from within the same sprout and same image. Lateral and longitudinal borders were defined if they were within 30 degrees of perpendicular or parallel to the sprout axis, respectively. Live imaging was performed using an Olympus FV10 microscope and the Olympus VivaView Incubator Fluorescence Microscope. Images were taken every 10 minutes. Students t-tests were used to analyze the data in figures $2.4 \mathrm{D}, 2.6 \mathrm{C}, 2.8 \mathrm{D}$ and $2.8 \mathrm{~F}$. Chai Square analysis was used in figure 2.8B. All error bars shown are standard error about the mean. 


\section{REFERENCES}

Gerhardt H, Golding M, Fruttiger M, Ruhrberg C, Lundkvist A, et al. 2003. VEGF guides angiogenic sprouting utilizing endothelial tip cell filopodia. The Journal of cell biology 161: 1163-77

Leitges M, Sanz L, Martin P, Duran A, Braun U, et al. 2001. Targeted disruption of the zetaPKC gene results in the impairment of the NF-kappaB pathway. Molecular cell 8: 771-80

Monvoisin A, Alva JA, Hofmann JJ, Zovein AC, Lane TF, Iruela-Arispe ML. 2006. VEcadherin-CreERT2 transgenic mouse: a model for inducible recombination in the endothelium. Developmental dynamics : an official publication of the American Association of Anatomists 235: 3413-22

Nakatsu MN, Davis J, Hughes CC. 2007. Optimized fibrin gel bead assay for the study of angiogenesis. Journal of visualized experiments : JoVE: 186

Rompani SB, Cepko CL. 2008. Retinal progenitor cells can produce restricted subsets of horizontal cells. Proceedings of the National Academy of Sciences of the United States of America 105: 192-7

Ruzankina Y, Pinzon-Guzman C, Asare A, Ong T, Pontano L, et al. 2007. Deletion of the developmentally essential gene ATR in adult mice leads to age-related phenotypes and stem cell loss. Cell stem cell 1: 113-26 


\section{CHAPTER III-Results}

This chapter is adapted from a paper submitted to Development in 2014. I wrote the first draft of the manuscript and made the figures. Dr. Victoria Bautch edited. Catherine Wright aided with the immunostaining of the sprouting angiogenesis assay. Jessica Heinz prepared the embryonic back samples, which I immunostained and imaged.

\section{A. Introduction}

Blood vessels deliver oxygen and nutrients through an extensive network that spans the body (Flamme et al 1993). Primitive blood vessels form during embryonic development in a process termed vasculogenesis. Complex, vascular networks are subsequently formed through angiogenesis, the creation of new vascular networks from preexisting blood vessels (Risau 1997). Sprouting angiogenesis is initiated by endothelial cells that sprout off and migrate away from parent vessels, creating a new vessel still connected to the parent vessel. This sprouting process has been described as utilizing a single unique migratory cell, or "tip cell", leading the nascent sprout away from the parent vessel (Gerhardt et al 2003). Recent work has shown this tip cell fate is not static; tip cells do not remain at the front of sprouts and stalk cells take their place at the front of sprouts (Arima et al 2011, Jakobsson et al 2010), demonstrating a more dynamic scenario than previously supposed in the classic tip cell model. 
As blood vessels form, polarity in the apical (luminal) to basal (abluminal) axis is established (Lee \& Bautch 2011, Lizama \& Zovein 2013). Established apical-basal polarity has been shown in capillaries (Horvat et al 1986), and in large arteries and veins (Zovein et al 2010) and is essential for lumen formation, which allows contiguous blood flow. Gross defects in blood vessels including failed lumenization of arterioles occurred with genetic loss of $\beta 1$ integrin, a transmembrane protein receptor that interacts with extracellular matrixes and surrounding cells (Zovein et al 2010). Furthermore, genetic loss of VE-Cadherin, an endothelial cell junction protein, results in loss of apical-basal polarity (Zovein et al 2010). These studies have started to elucidate polarization in angiogenesis but much remains unknown, including how these polarity proteins interact, the timing of polarization, and the relationship between lumenization and polarization. Polarization at the early steps of vasculogenesis can be observed in the developing mouse dorsal aorta, allowing insight into the timing of polarization during vasculogenesis (Strilic et al 2009). However, to date the critical question of where and when apical-basal polarity is established during angiogenesis remains unanswered.

Recent work has shown links between apical-basal polarity and lumen formation in epithelia (Bryant et al 2010), but little is known about their relationship in angiogenesis. Lumen formation is a necessary process in blood vessel formation and can occur via multiple mechanisms. One proposed mechanism is cell hollowing (Kamei et al 2006), whereby one endothelial cell forms a lumen within itself that subsequently connects to other lumenized cells. Another mechanism is cord hollowing, where the lumen forms between two or more neighboring cells. 
Visualizing cell-cell borders with zonula occludens-1 (ZO1) in zebrafish dorsal longitudinal anastomotic vessels demonstrate lumens in between cells, suggesting that these vessels form by cord hollowing (Herwig et al 2011). Additionally, imaging of the mouse dorsal aorta supports lumen construction through hollowing between multiple cells in a cord (Strilic et al 2009). These results have given preliminary insight into polarization and lumen formation in blood vessel formation.

Atypical PKC (aPKC) is a well-known polarity protein, active in many cell types and cellular contexts (Ohno 2001). In mammals there are two isoforms, aPKC zeta and aPKC iota(Akimoto et al 1994, Ono et al 1988, Selbie et al 1993), which share $72 \%$ amino acid identity and exhibit functional redundancy (Akimoto et al 1994). In multiple contexts, aPKC forms a complex with Par-6 and Par-3 to help initiate apical-basal polarity (Horikoshi et al 2009, Wodarz et al 2000). aPKC plays a role in both polarization and lumen formation within epithelial tubes (Bryant et al 2010, Horne-Badovinac et al 2001, Whyte et al 2010). It has been demonstrated that aPKC is necessary for proper blood vessel formation (Koh et al 2008), and that aPKC $\lambda$ is necessary for inhibiting VEGF response behind the vascular front (Nakayama et al 2013). Yet the role of aPKC zeta and those aPKC lambda functions that are redundant with aPKC zeta in establishing polarity during angiogenesis are unknown.

Here, we describe a novel cellular topology discovered in blood vessel sprouts. Utilizing confocal imaging of mosaically labeled endothelial cells, we show consistent and maintained overlap of at least two endothelial cells at the tips of angiogenic sprouts. This cellular arrangement creates a longitudinal cell-cell border 
that enables and supports apical-basal polarization. We propose that this novel cellular topology allows apical-basal polarity to be established in new sprouts, supporting lumen formation via cord hollowing. This cellular arrangement is affected by aPKC, as genetic loss of one of the aPKC isoforms affects proper overlap, which corresponds with perturbed apical-basal polarity establishment and affects lumen formation

\section{Results}

\section{B. Sprout Tips are Composed of Two Overlapping Cells}

The widely accepted model of angiogenic sprouting describes a single cell, the tip cell, leading nascent sprouts (Siekmann et al 2013). In contrast to this, we observed that angiogenic sprouts often had multiple overlapping cells at the distal end (Fig 2.1a,b). To determine the frequency of overlapping tip cells, we first utilized the sprouting angiogenesis assay whereby human umbilical vein endothelial cells (HUVEC) attach to a microcarrier bead and are embedded into a fibrin matrix. Cells migrate, sprout and lumenize similar to in vivo sprouting angiogenesis (Nakatsu et al 2007). We infected two populations of HUVEC with lentivirus expressing reporters of different colors, eGFP (green) or tdTomato (red), and mixed the populations to create mosaic labeled spouts (Fig 2.1a). We allowed cells to grow for 3 days and examined the distal portion of sprouts. As expected, we saw filopodia extending at the distal end of sprouts, an indicator of tip cells. To understand the cellular topology of the distal end of sprouts we measured tip cell overlap in sprouts where the leading two cells were different colors. Overlap measured the percentage the minor tip cell overlapped the distance from the back of the major tip cell nucleus to 
the leading edge of the major tip cell (Fig 2.1c). When measuring the amount of overlap between two cells leading sprouts, we observed that the majority of sprouts have overlapping cells ( $n=38$, Fig 2.1d). Over $50 \%$ of observed sprouts have more than $75 \%$ overlap.

To determine if this novel topology is present in vivo we examined the vascular front of retinal vessels in the postnatal mouse. We generated mosaic labeled vessels by mating mice expressing a ubiquitous inducible Cre, UBCCre/ESR1 (Stahl et al 2010), and mice expressing tdTomato upon Cre excision, R26R tomato (Ruzankina et al 2007). Using low doses of tamoxifen to induce excision in a subset of cells, we obtained a mix of red and non-red cells in the vasculature. We stained retinas with isolectin, a pan endothelial membrane marker to visualize all endothelial cells. We measured tip cell overlap in sprouts that had a red endothelial cell and an "unmarked" endothelial cell as the two most distal cells. These measurements showed that the second most distal cell overlapped the major tip cell for an average of $80 \%$ of the major tip cell length (Fig 2.1e,f). Further, overlap of at least $76 \%$ of the major tip cell length was found in $74.3 \%$ of sprouts and all sprouts measured had an overlap above $47 \%$. These overlap data demonstrate that overlap is a prevalent topology in the mouse retina vasculature. To confirm that this cellular topology exists in other tissues, we analyzed blood vessels that form in the embryonic back at embryonic day 12.5 (E12.5). Mosaic sprouts in the E12.5 were generated using a tdTomato reporter with VE-Cadherin Cre. At E12.5, mosaic expression of VE-Cadherin leads to mosaic expression of tdTomato. Analysis of sprouts in the embryonic back also showed overlapping tip cells in sprouts, with $83 \%$ 
of sprouts having a minor tip cell that overlapped the major tip cell for over $50 \%$ of the major tip cell length $(\mathbf{F i g} \mathbf{2 . 2 a}, \mathbf{b})$. Combined, these data show that two or more cells overlap in a consistent cellular architecture in multiple angiogenic contexts.

Recent work has shown that tip cells switch place with a stalk cell every 4-7 hours on average (Arima et al 2011, Jakobsson et al 2010). Therefore we would predict that cellular overlap between tip cells and stalk cells would exist while tip cells are switching. We hypothesized that tip cell switching was not sufficient to explain the high prevalence of overlap. To test this hypothesis, we performed live imaging of the mosaic labeled HUVEC sprouts over the course of 16-20 hours (Fig 2.3a). Consistent with previous studies, we observed that the major and minor tip cell nuclei switched places approximately every 5.5 hours (Fig $\mathbf{2 . 3 b}$ ), which is consistent with the previously published range of 4-7 hours (Arima et al 2011, Jakobsson et al 2010). Notably, tip cell overlap, as previously measured, was consistently maintained ( $\mathrm{n}=12$ movies, 100 time points each Fig 2.3c), and overlap was maintained continuously throughout multiple periods of nuclei switching. This demonstrates that cellular overlap is consistently maintained, and is not simply a byproduct of tip cell switching.

Because tip cell overlap was maintained, regardless of cell switching, we analyzed the movement of the leading edge of the cells compared to the movement of the body of the cells. To determine the cellular dynamics exhibited during maintained overlap, we measured the relative velocity of both the nuclei and the leading edge of the major and minor tip cells. Surprisingly, the movement of the tip cells' leading edge did not correlate with the movement of its nucleus ( $r$-value $=.08$, 
$\mathrm{n}=6$ cells, 100 time points, Fig 2.3d). This demonstrates that the leading edges of the tip cells stay in close proximity, maintaining overlap, with movements uncorrelated to the movement of the cell body behind.

To maintain cellular overlap, tip cells would either have to sustain near equal velocities, or have velocities that alternate at high rates. Based on the dynamic nature of endothelial cells, we hypothesized that the tips of cells dynamically change velocities over time. To analyze this, we looked at the relative velocities of the major and minor tip cell leading edges to see which cell was migrating with a higher velocity. The leading edge of the two tip cells alternated which was migrating distally faster $48.5 \%$ of the time points measured (12 movies, 100 time points Fig 2.3e). This suggests that the major and minor tip cell dynamically alternate their relative velocities, with the leading edge of each cell extending faster on average every other 20 minutes. This data provides evidence that velocity switching between the two leading tip cells leads to maintained overlap at the front of sprouts.

\section{Blood Vessel Sprouts Establish and Polarize along the Longitudinal Border between the Major and Minor Tip Cell}

The novel observation that sprouting vessels have two overlapping cells at the tip, rather than having a single "tip cell", led us to investigate how sprouts polarize to establish apical-basal polarity. In early mouse dorsal aorta development, apical-basal polarity establishment occurs at the membranes of two cells at the border between these cells (Strilic et al 2009); therefore, we hypothesized that the apical domain is established along the longitudinal border created by the cellular overlap in angiogenic sprouts. To confirm polarity in established vessels and 
establish a quantitative method for analyzing polarization we analyzed polarization of mature vessels, vessels that have been formed, lumenized and have had time to establish polarity. We stained HUVEC sprouts with apical and basal polarity markers. Mature, lumenized vessels close to the bead expressed the apical marker podocalyxin (PODXL) on the luminal surface and the basal marker collagen IV (Coll IV) on the abluminal vessel surface (Fig 2.4a). In the mouse retina, we analyzed lumenized arteries and veins. Consistent with previous research, these vessels displayed polarized signal for both PODXL and $\beta 1$ integrin, with PODXL localized to the luminal or apical surface, and $\beta 1$ integrin basally localized in lumenized vessels behind the vascular front (Fig 2.4b). To quantitatively examine polarization, we used pixel intensity line plots. Line plots of isolectin determined the location of all membranes, and the pixel intensity of various markers in these areas was measured (Fig 2.4c). Intenisty of the luminal marker, D488, is located interior to the apical membrane, and DAPI is strongly localized between the two membranes (Fig 2.4d) PODXL pixel intensity at the apical surface is significantly higher than the basal surface, whereas collagen IV and $\beta 1$ integrin have a significantly higher pixel intensity level at the basal surface (Fig 2.4d). These data confirm that apical-basal polarity is established in lumenized vessels, and that our chosen markers faithfully report this.

We then wanted to determine where along the proximal-distal sprout axis apical-basal polarity is established. We therefore analyzed developing sprouts in the sprouting angiogenesis assay that do not yet have detectable lumens based on membrane staining with PECAM. However, the apical marker PODXL is observed at 
the longitudinal cell-cell border between the two tip cells, and the basal marker $\beta 1$ integrin is localized to the abluminal surface to the distal end of the sprout (Fig 2.5a). To determine if sprouts are polarized comparably in in vivo sprouts, we analyzed the vascular front of mouse retinal vessels. In sprouts, PODXL is localized to the longitudinal cell-cell border the majority of the length of the sprout (Fig 2.5b). We wanted to see if the polarized localization of PODXL is specific to the longitudinal cell-cell border, or if it is indiscriminately found at cell-cell borders at the vascular front. (Fig 2.6a, b). Line plot analysis of PODXL staining intensity revealed significantly higher levels at the longitudinal border relative to the lateral border (Fig 2.6c). This demonstrates that PODXL, normally found at the apical membrane, is asymmetrically localized to the longitudinal cell borders in sprouts at the vascular front of mouse retinas. This suggests that the apical domain is likely established at the longitudinal cell-cell border

Lumens have been shown to form between two cells in zebrafish intersegmental vessels and in the mouse aorta (Blum et al 2008). Given the establishment of apical polarity in nascent sprouts, we hypothesized that the overlap within sprouts allows lumen formation along the polarized longitudinal border. FITC conjugated dextran (D488) was perfused to visualize patent lumens in the mouse retina. Evidence of patent lumens were detected in sprouts by the presence of dextran, which localized to the longitudinal border (Fig 2.7). This demonstrates that lumens are already formed between the two leading cells in sprouts, and suggests that polarity at the longitudinal border is leading to lumen formation. 


\section{D. aPKC zeta knock down disrupts cell overlap leading to a defect in lumen formation}

These data suggest that apical polarity is established at the longitudinal border of sprouts created by the cellular topology within these sprouts. We next wanted to study the molecular regulators of this process. Atypical protein kinase C (aPKC) is necessary for multiple aspects of polarity and is therefore a good candidate for being involved in setting up apical basal polarity in angiogenesis. aPKC lambda and zeta are the two mammalian atypical PKC isoforms. They have been shown to be necessary for proper sprout formation (Koh et al 2008), but their specific role is unknown. This made the aPKCs a good candidate for affecting sprouting angiogenesis. When we examined the mouse retina vasculature of aPKC zeta null mice (Leitges et al 2001), we observed that the overall morphology of the vascular network was unchanged. The sprouts in the network were the same length and width as wildtype littermates. Surprisingly, we observed that aPKC zeta null vessels have a lower amount of tip cell overlap, as based on nuclei presence in sprouts at the vascular front (Fig 2.8a, b).

The longitudinal border between tip cells is the site of polarity formation; we therefore hypothesized that this reduction in cell overlap would affect the establishment of polarity. To test this, we looked at the localization of PODXL to the longitudinal border within aPKC zeta null sprouts. Indeed, the localization of PODXL at the longitudinal border of aPKC zeta mice revealed an increased distance from

the front of the sprout to the start of PODXL staining (Fig 2.8c, d). This shows that in 
sprouts where cellular overlap is reduced, apical polarity is not able to form in the proper location distally within the sprout.

Because apical-basal polarity is necessary for lumen formation, we hypothesized that eliminating tip cell overlap would also lead to defects in lumen formation. To test this we used dextran perfusions to label the patent lumens of aPKC zeta null mice, where tip cell overlap is eliminated, compared to wildtype littermates. The measured distance from the tip of the sprouts to the patent lumen was significantly higher in the mutant mice (Fig 2.8e, f). This demonstrates a lumen formation delay in aPKC zeta null mice.

\section{E. Conclusions}

This work shows that angiogenesis involves the intimate association of at least two endothelial cells at sprout tips of mammalian vessels, in a HUVEC sprouting assay, in the embryonic back, and in the postnatal retina. This association is maintained by similar velocities and by alternation of maximal velocities, and it sets up a longitudinal apical border that is the site of lumen formation (Fig2.9). Genetic loss of aPKC $\zeta$ results in small but significant changes in cell overlap, polarization, and lumen formation, suggesting that these processes influence each other and get input from aPKC. These surprising results suggest that the paradigm of a single endothelial cell at the sprout tip needs revision, and the revised model has several implications. Our model implies a cord hollowing mechanism of lumen formation at the tip of angiogenic sprouts. It also suggests that the apical-basal polarity axis is initially set up perpendicular to the sprout axis, which is its ultimate position. The model also suggests that the relationship of the two endothelial cells at 
the tip have a complex, or interchanging, relationship in terms of Notch signaling, which has previously been modeled on the basis of a single tip cell and a binary interaction. Ligand activation of DII4 in the tip cell is predicted to activate Notch in the proximal stalk cell, promoting lateral inhibition of sprouting. The finding that two sprouting endothelial cells occupy the tip suggests a non-binary Notch signaling scenario. 


\section{F. Figures}

Figure 2.1. Multiple cells occupy the tip position in sprouts. A) Sprout formed from HUVEC infected with either GFP-expressing lentivirus or tdTomato-expressing lentivirus and mixed prior to coating the beads. Two cells overlap to form the sprout. B) Previous model of cell stacking in sprouts and the observed cell architecture of two overlapping cells. C) Schematic of percent overlap measure in sprouts. Measurements were made from the base of the major tip cell's nucleus to the distal edge of the minor tip cell. $\quad$ D) Percentage of overlap seen in HUVEC sprouting assay $(n=24)$. E) Mouse retina vasculature sprout with one endothelial cell expressing tdTomato and adjacent endothelial cell negative for tdTomato. Retinas were stained with isolectin (green, endothelial marker) and DAPI (blue, nuclear marker). Orthogonal views and diagrams show overlap of endothelial cells near the front of the sprout. F) Amount of sprout overlap in mouse retina vasculature sprouts $(n=35)$. 


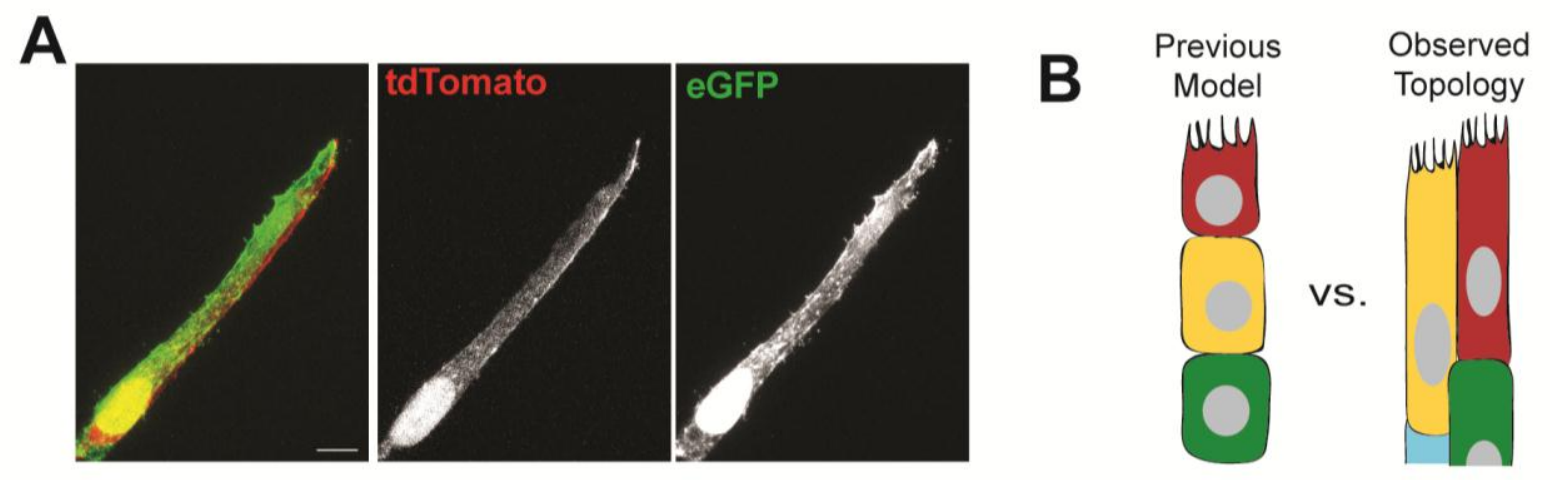

C

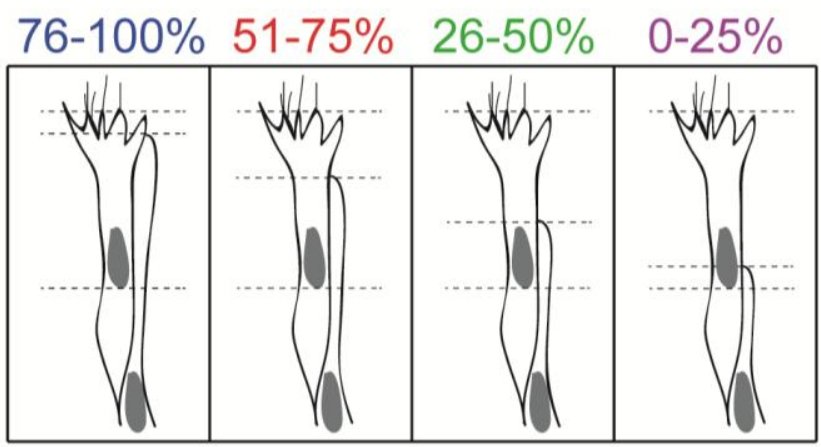

D

HUVEC Sprouting

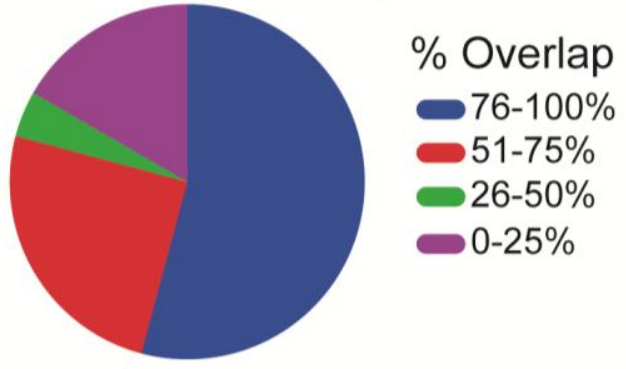

E

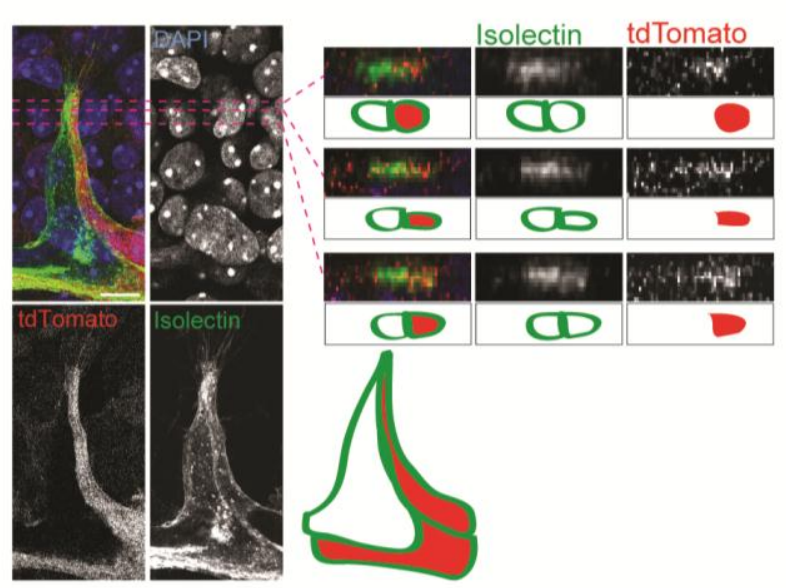

$F$
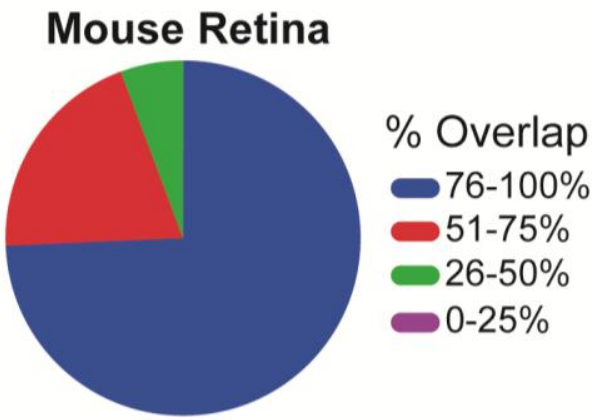
Figure 2.2. Multiple cells occupy the tip position in embryonic sprouts. A)

Sprout formed in the embryonic back with one endothelial cell expressing tdTomato and adjacent endothelial cell negative for tdTomato. Sprout is stained with PECAM (green, endothelial membrane marker) and DAPI (white, nuclear marker). B)

Percentage of overlap seen in embryonic back ( $n=12$ sprouts). 
A

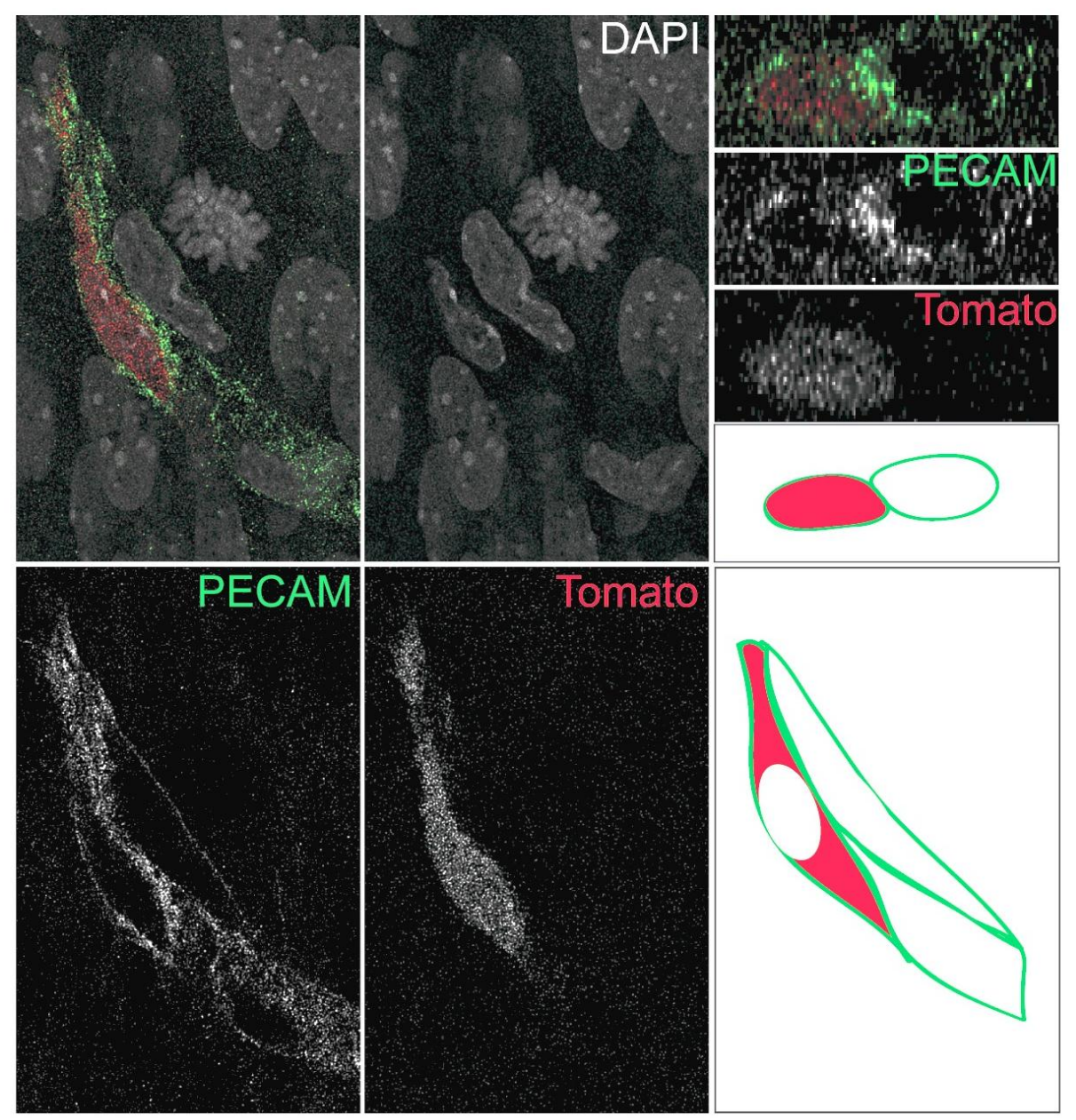

B

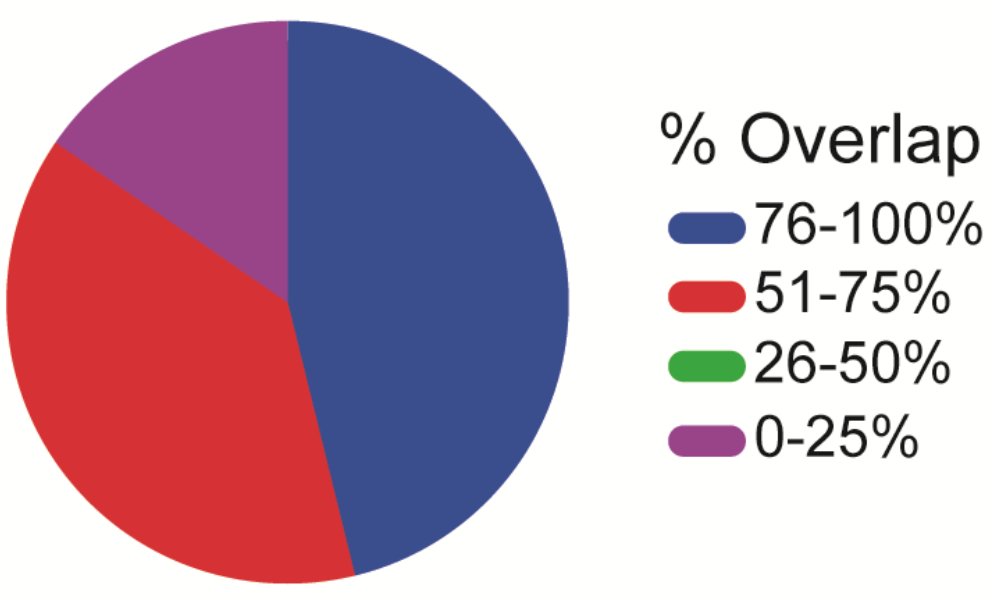


Figure 2.3. Endothelial cell dynamics lead to cell overlap in sprouts. A) Time lapse images of a HUVEC sprouting angiogenesis sprout. The tips of the tdTomatoexpressing and GFP-expressing cells are indicated by red and green arrows respectively. B) Bar graph showing the average duration as the most distal cell measured based on the center of the nuclei or based on the leading edge of the cells ( $n>1200$ time points, 12 movies 1000 minutes each) Error bars, +/-s.e.m., Student's T-test. C) Percentage of overlap seen in HUVEC sprouting assay for every time point in each movie ( $n>1200$ time points, 12 movies). D) Scatterplot of the velocity of the nucleus and the velocity of the tip for the two most distal tip cells. Velocities were measured by taking the position of either the center of the nucleus or the most distal point of the cell lamelapodia. Distance traveled was measured only in the axis of the sprout, and velocity was calculated at every time point, 10 minutes. R-value is .082 ( $n=303$ time points). E) Graphs from two representative movies show the percent overlap overtime as well as the relative velocity of the leading two cells based on the leading edge. 
A
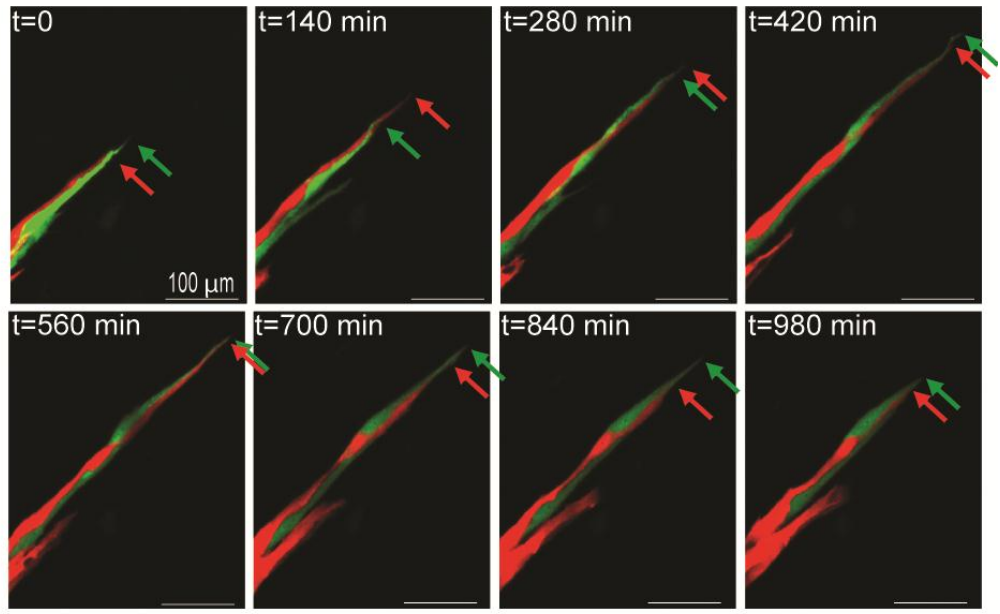

$\mathrm{t}=980 \mathrm{~min}$
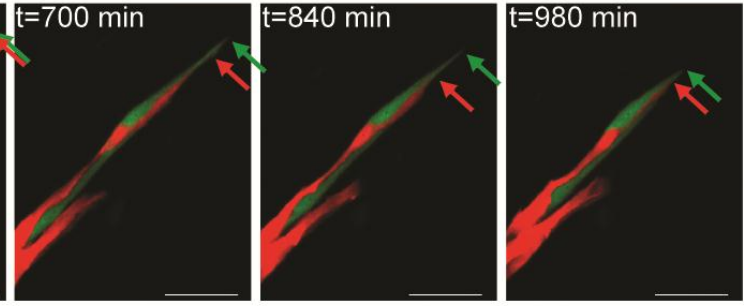

C
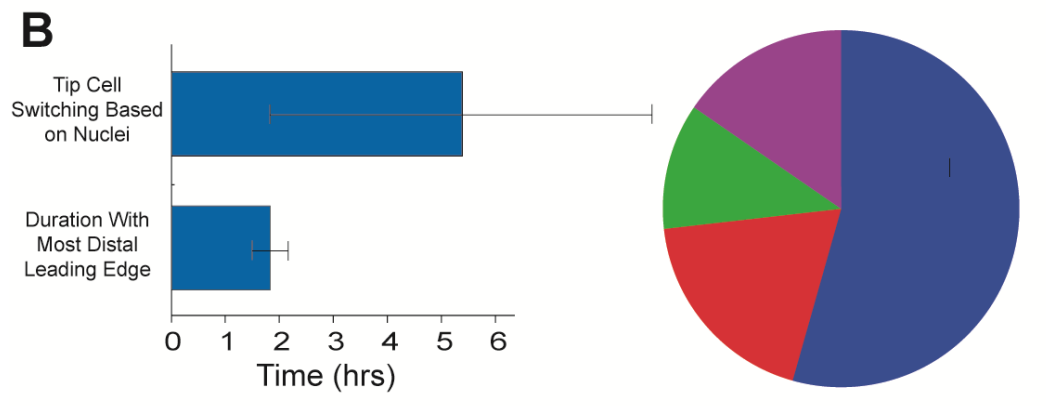

$\%$ Overlap

- $76-100 \%$

$51-75 \%$

$26-50 \%$

$0-25 \%$

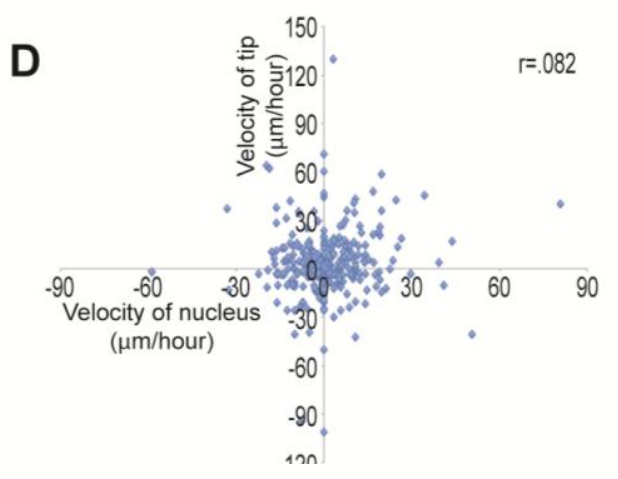

E

Individual Movies
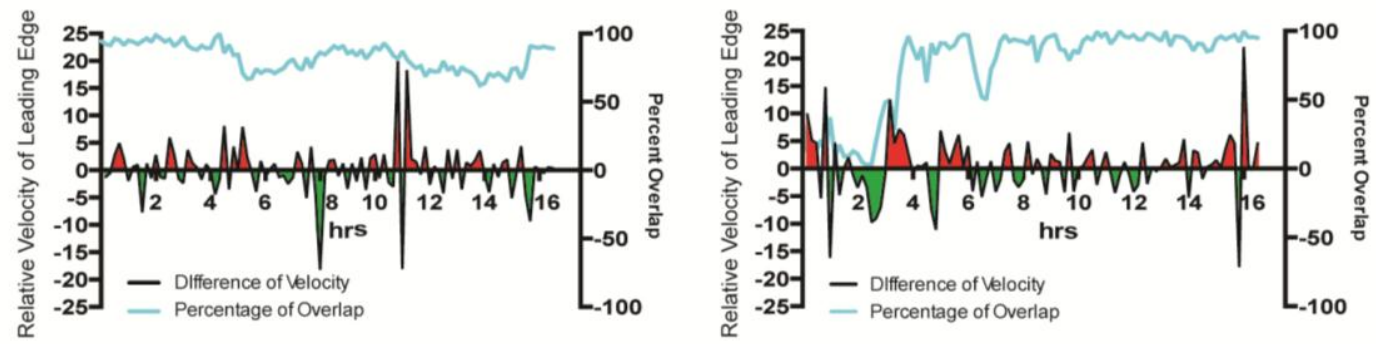
Figure 2.4. Sprouts exhibit apico-basal polarity in mature blood vessels. A) Single HUVEC lumenized sprout stained for collagen IV (blue, basal), podocalyxin (PODXL, red, apical), and DAPI (white, nuclear), showing apical basal polarization. B) Proximal area of a retinal vein, stained with PODXL (red, apical), isolectin (green, endothelial), $\beta 1$ integrin (blue, basal) and DAPI (white, nuclear). Orthogonal views and diagrams show a polarized, lumenized vessel. C) Line-scan of polarity marker intensity from the luminal space of the vessel outwards. Pixel intensities shown for $\beta 1$ integrin (blue, basal), dextran perfusion-D488 (purple, patent lumen), PODXL (red, apical), isolectin (green, endothelial), and DAPI (black, nuclear). The peaks of intensity corresponding to the apical and basal surfaces are labeled with black arrows. D) Average ratio of basal to apical pixel intensity to Isolectin pixel intensity for PODXL, collagen IV and $\beta 1$ integrin ( $n=26,12,20$ respectively) ${ }^{*}, p<0.05$. 

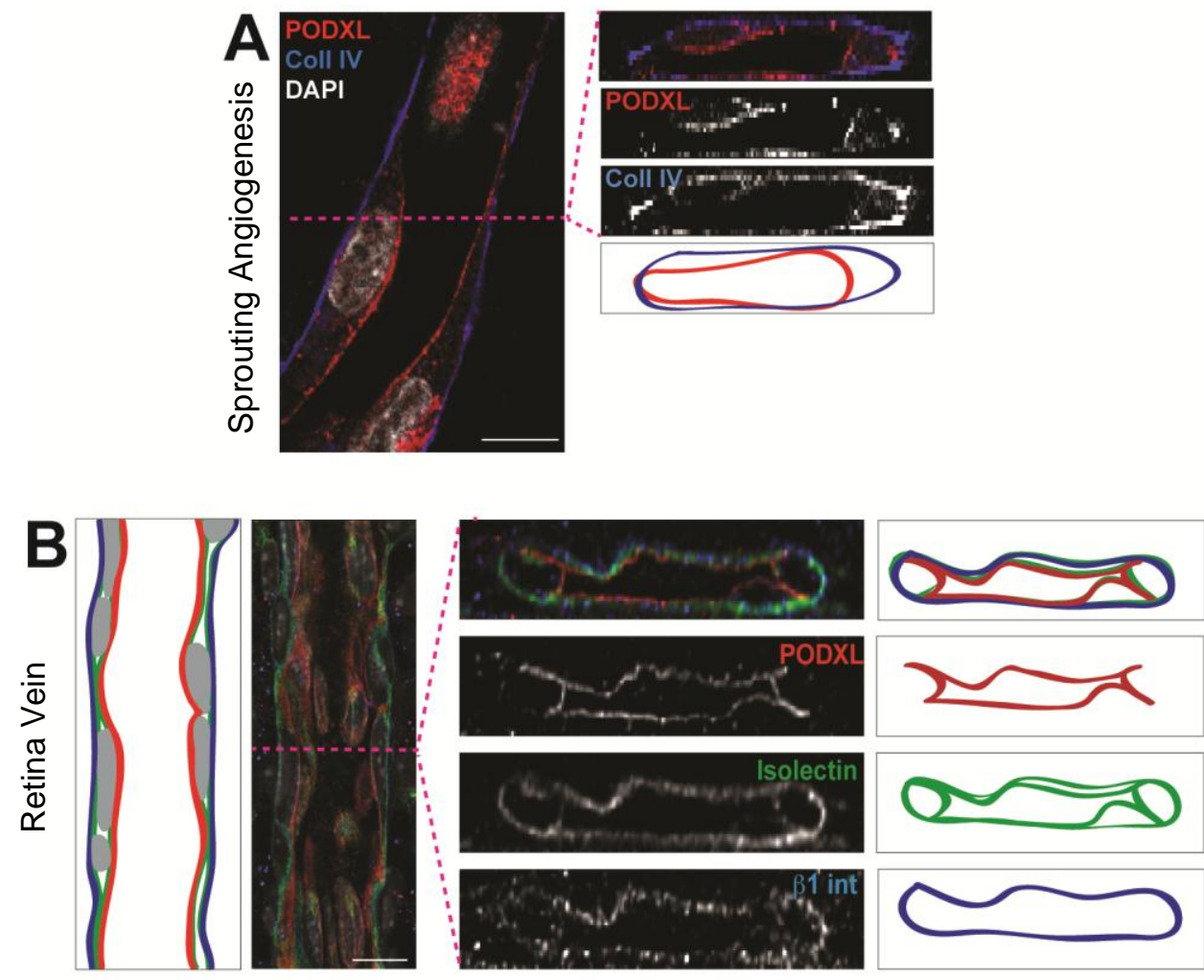

C
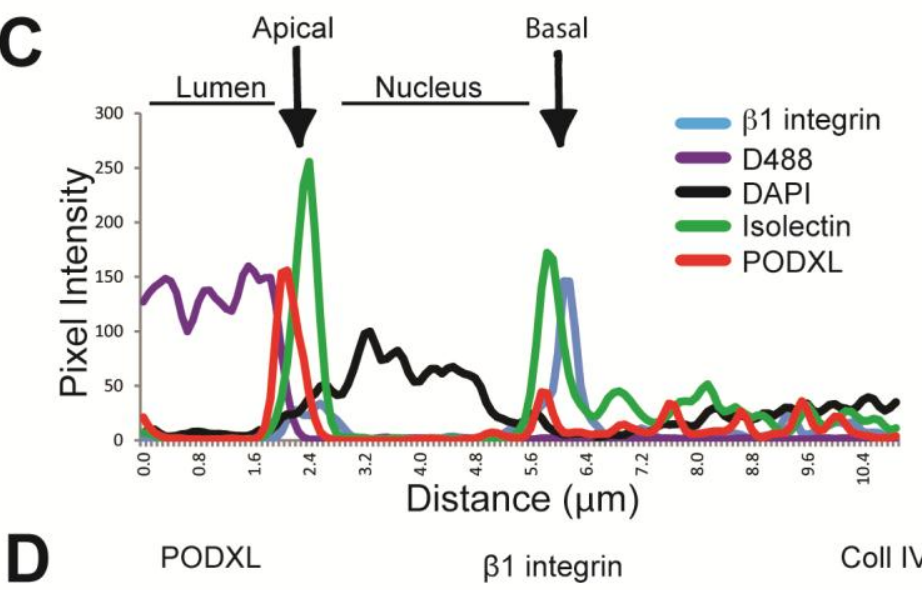

$\beta 1$ integrin

Coll IV
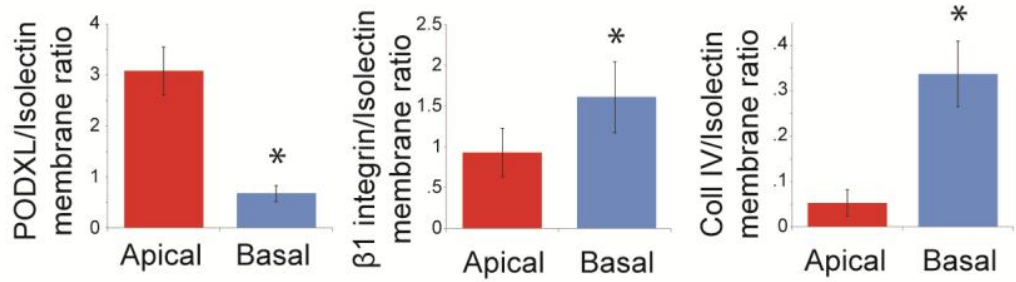
Figure 2.5 Sprouts polarize at cell-cell border in sprout. A) Distal tip of a HUVEC sprout that is not yet visibly lumenized, stained with antibodies against $\beta 1$ integrin (blue, basal), PODXL (red, apical), and the nuclear dye DAPI (white, nuclear. Orthogonal views and diagrams below orthogonal views indicate localization of apical and basal markers. B) Retinal sprout at the vascular front stained with PODXL (red, apical), isolectin (green, endothelial), and DAPI (white, nuclear). Orthogonal views and diagrams show PODXL localized at the longitudinal cell-cell border. Scale bars represent $10 \mu \mathrm{m}$. 
A
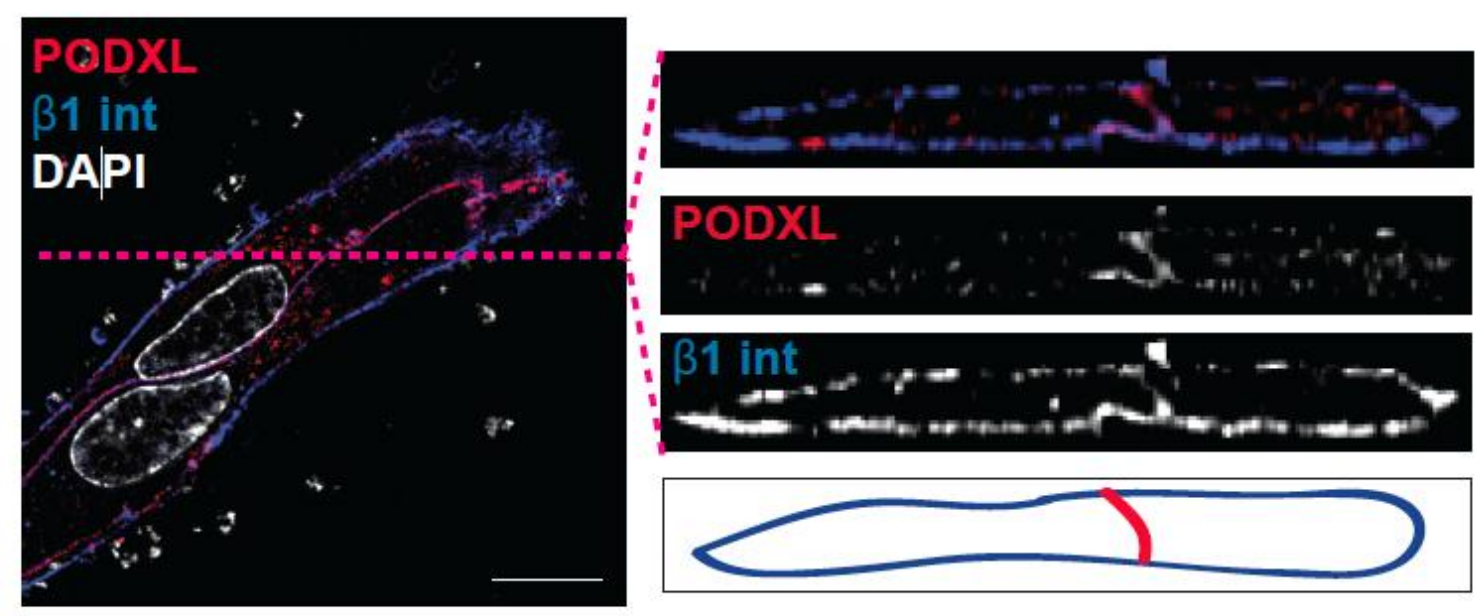

B

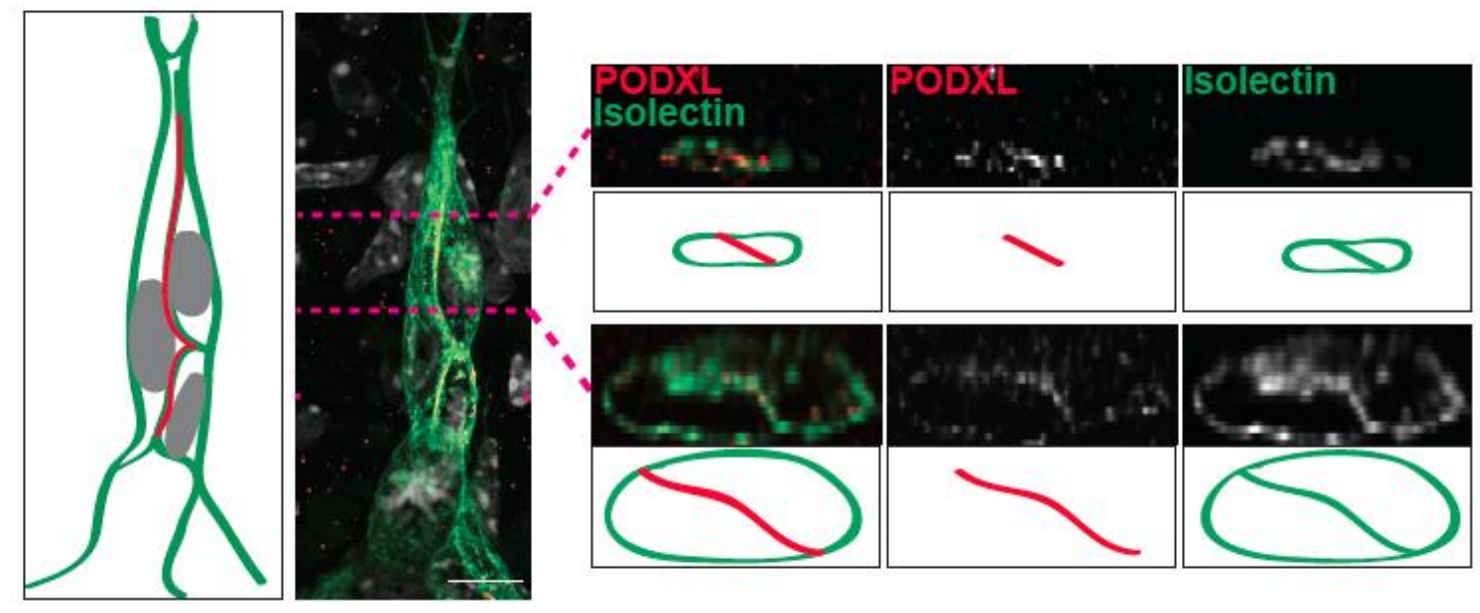


Figure 2.6 PODXL preferentially localized to the longitudinal border in sprouts A) Retinal sprout at the vascular front stained with PODXL (red, apical), Isolectin (green, endothelial) and $\beta 1$ integrin (blue, basal). Arrow identifies the lateral cell-cell border, and arrowhead identifies the longitudinal cell-cell border. B) Pixel intensity of PODXL (red) and isolectin (green). The peaks of isolectin intensity corresponding to the lateral and longitudinal cell-cell borders are labeled with black arrows. C) Relative PODXL intensity in longitudinal vs. lateral borders in retinal sprouts at the vascular front ( $n=16$ sprouts). Error bars, +/- s.e.m., Student's T-test.. *,$p<0.05$. Scale Bar represents $5 \mu \mathrm{m}$. 
A
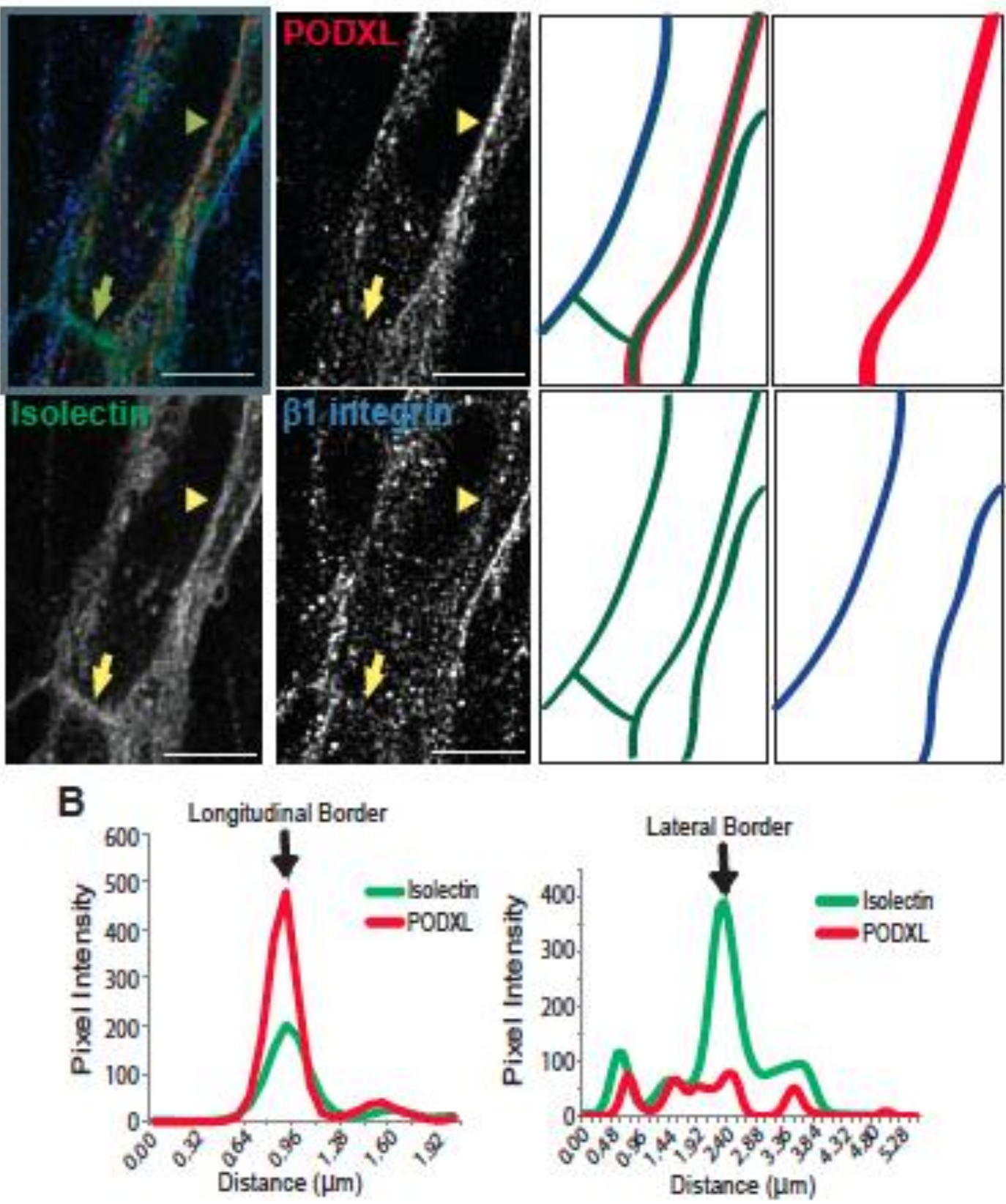

C

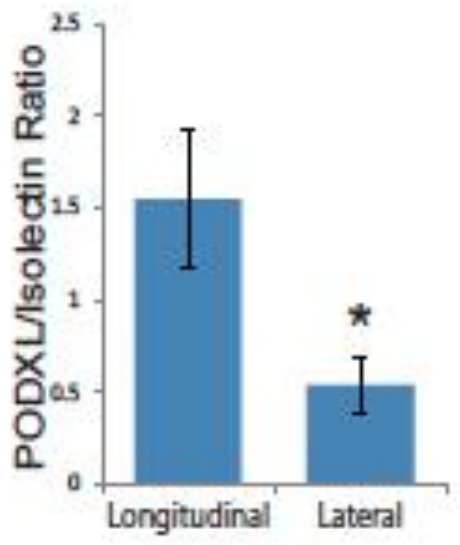


Figure 2.7 Retinal sprouts have patent lumens formed between cells. Retinal sprout at the vascular front perfused with FITC conjugated dextran (green), then stained with isolectin (white, endothelial) and DAPI (blue, nuclear). Scale Bars represent $10 \mu \mathrm{m}$. 


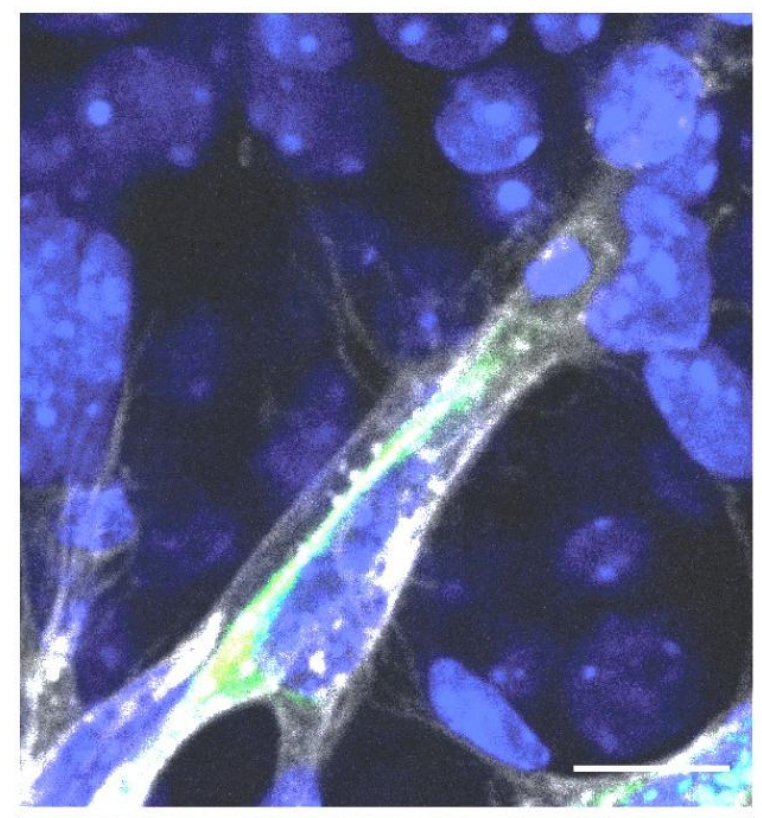

Isolectin
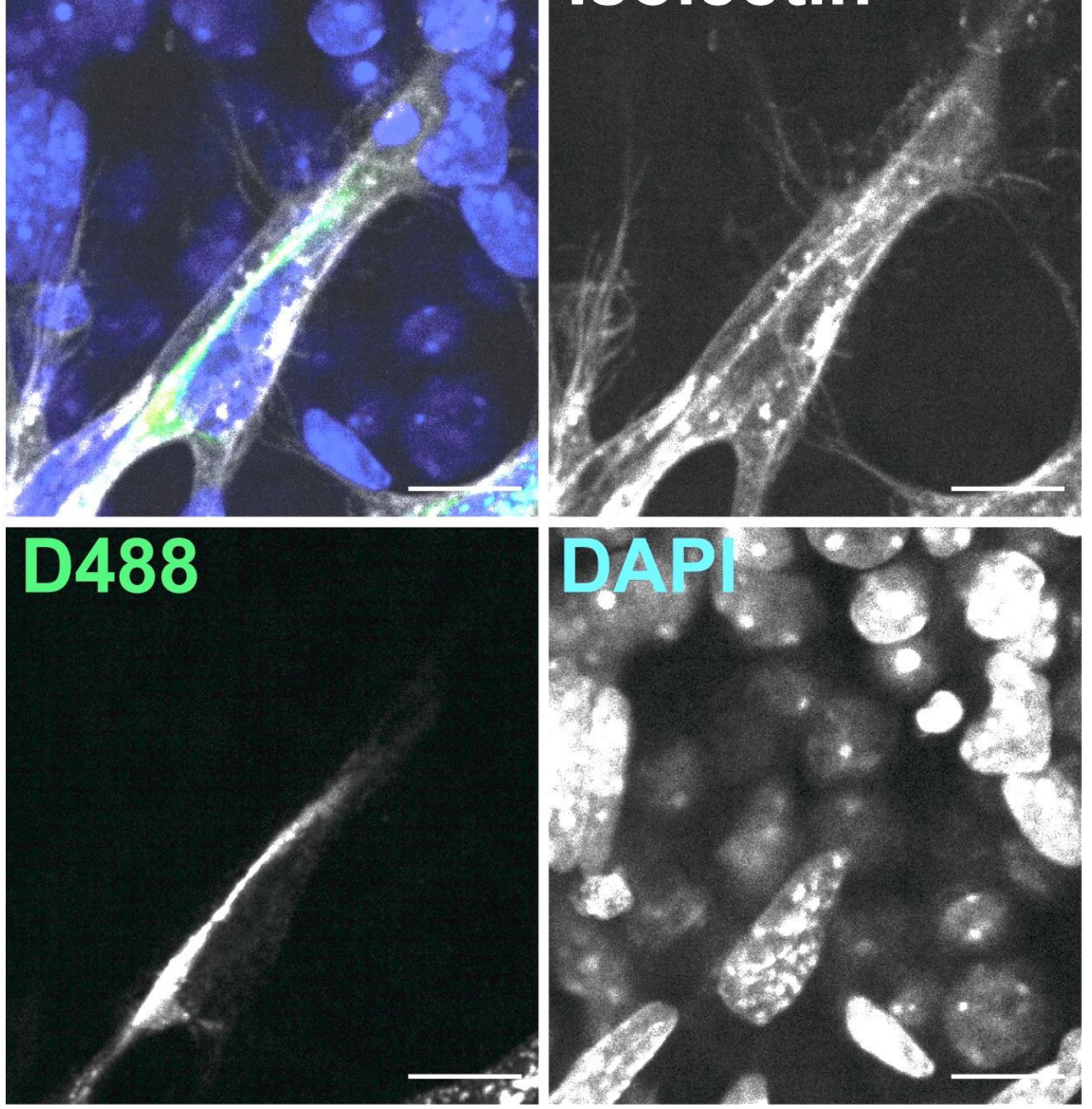
Figure 2.8 Loss of aPKC zeta perturbs cellular architecture in sprouts. A,C,E) Retinal sprouts of wildtype littermates and aPKC zeta null mice. A) Sprouts stained with isolectin (green, endothelial) and DAPI (blue, nuclear). Red dashed lines show nuclei within the sprouts. B) Percentage of sprouts containing overlapping nuclei or separated nuclei in wild-type and aPKC zeta null mice. Error bars, +/- s.e.m., Student's T-test. ( $n=43$ wt littermates, $n=48$ aPKC zeta), ${ }^{* *}, P \leq 0.01$. C) Sprouts stained with isolectin (green, endothelial), PODXL (red, apical) and DAPI (blue, nuclear). White lines indicate distance from sprout front to PODXL localization. D) Average distance from the tip of the sprout to localized PODXL in wild-type and aPKC zeta null mice. Error bars, +/- s.e.m., Student's T-test. ( $n=42$ wt littermates, $\mathrm{n}=49$ aPKC zeta). * $\mathrm{P} \leq 0.05$. E) Sprouts perfused with FITC conjugated dextran (pseudocolored red) stained with isolectin (green, endothelial) and DAPI (blue, nuclear). White lines indicate distance from sprout front to dextran-FITC lumen label F) Average distance from the front of a sprout to first detection of a patent lumen. Error bars, +/- s.e.m., Student's T-test. ( $n=172$ wt littermates, $n=174$ aPKC zeta), **, $\mathrm{P} \leq 0.01$. Scale Bars represent $10 \mu \mathrm{m}$. 


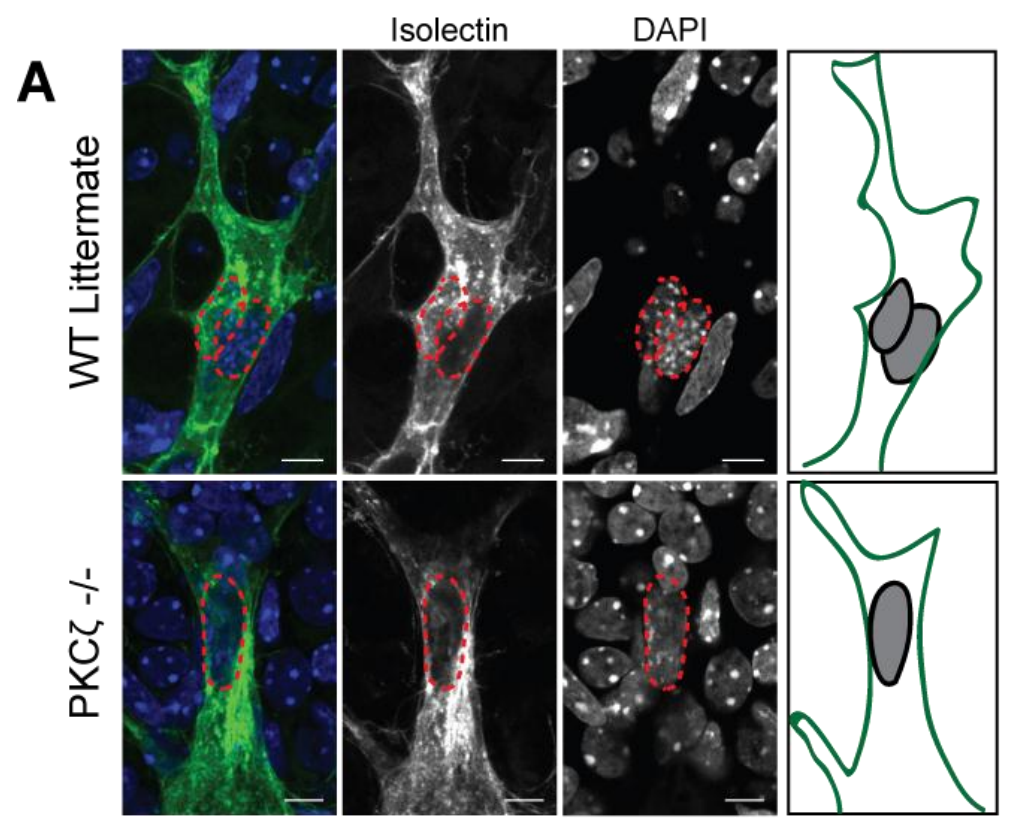

B

C

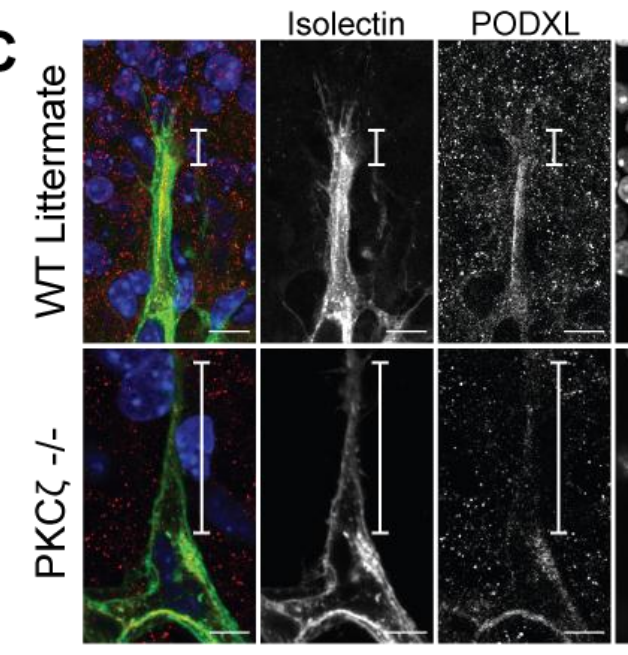

E
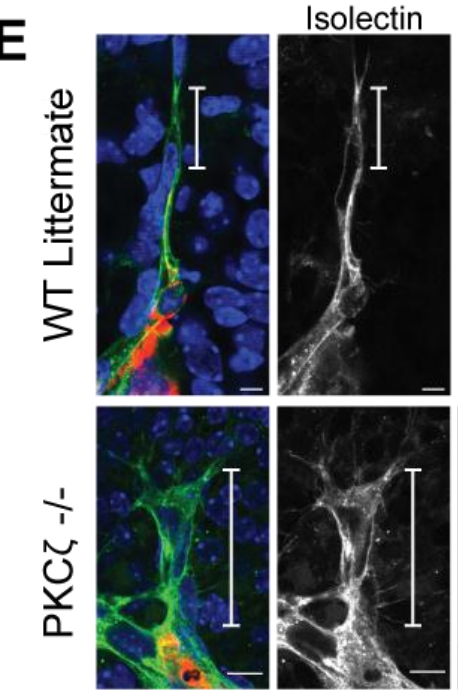
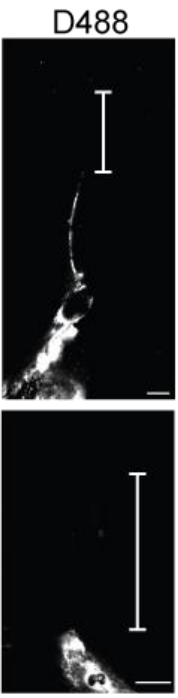

DAPI
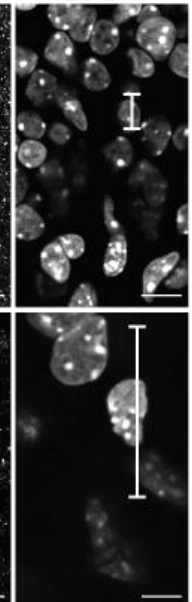

DAPI
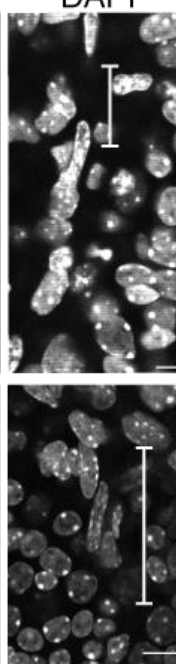
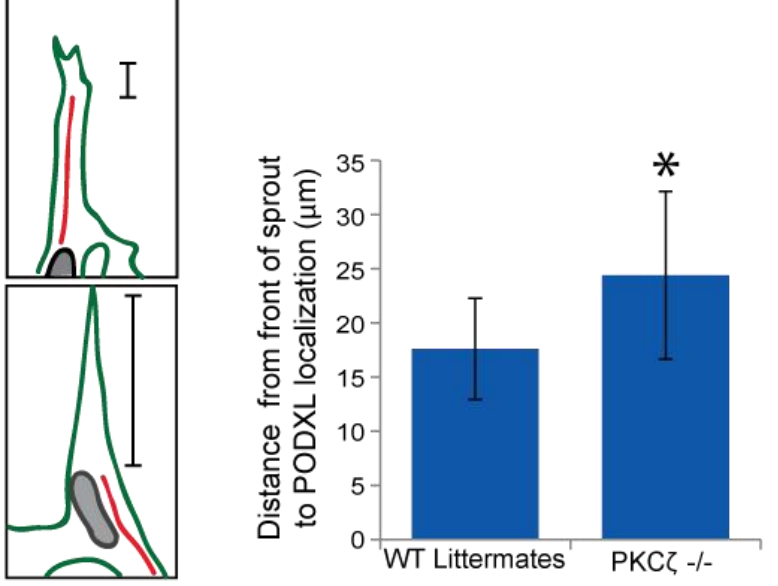

F
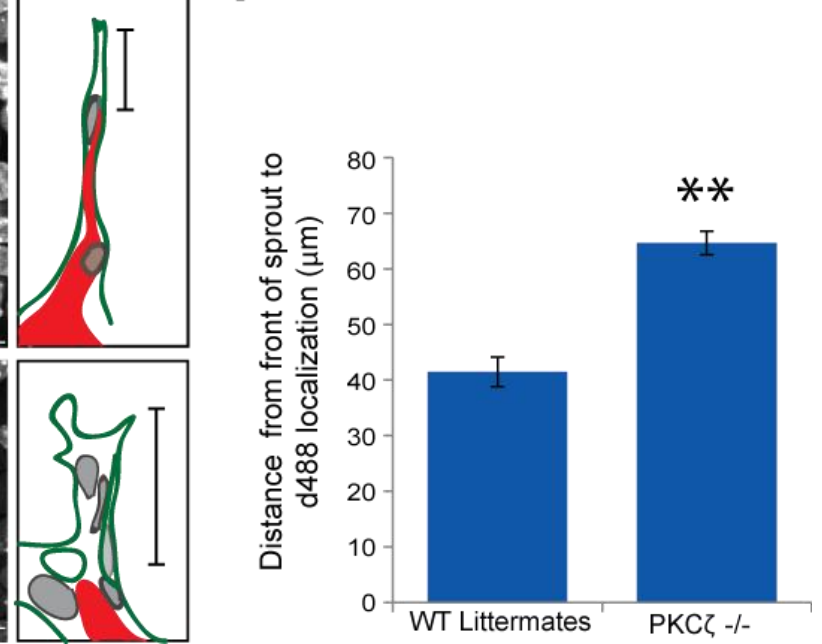

- Nuclei Seperated

- Nuclei Overlapped

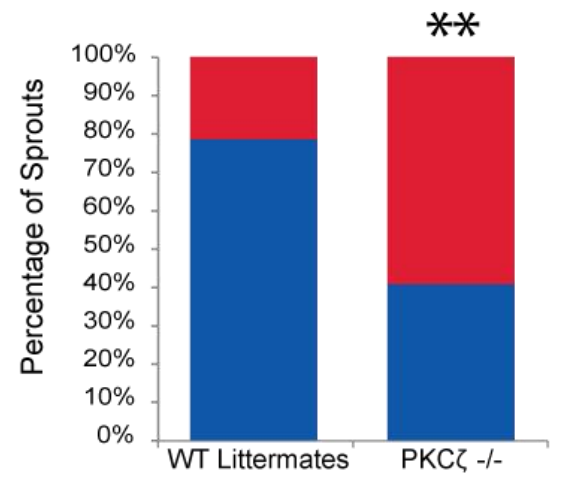

D 
Figure 2.9 Model of sprout formation. The schematic model shows the formation of angiogenic sprouts. In wild type sprouts, two cells overlap creating a longitudinal border. Polarization at the longitudinal border occurs. Lumen formation occurs between two cells along the longitudinal border. In aPKC $\zeta$ null sprouts cell overlap is not maintained. Polarization and lumenization is not able to occur as close to the sprout front. 


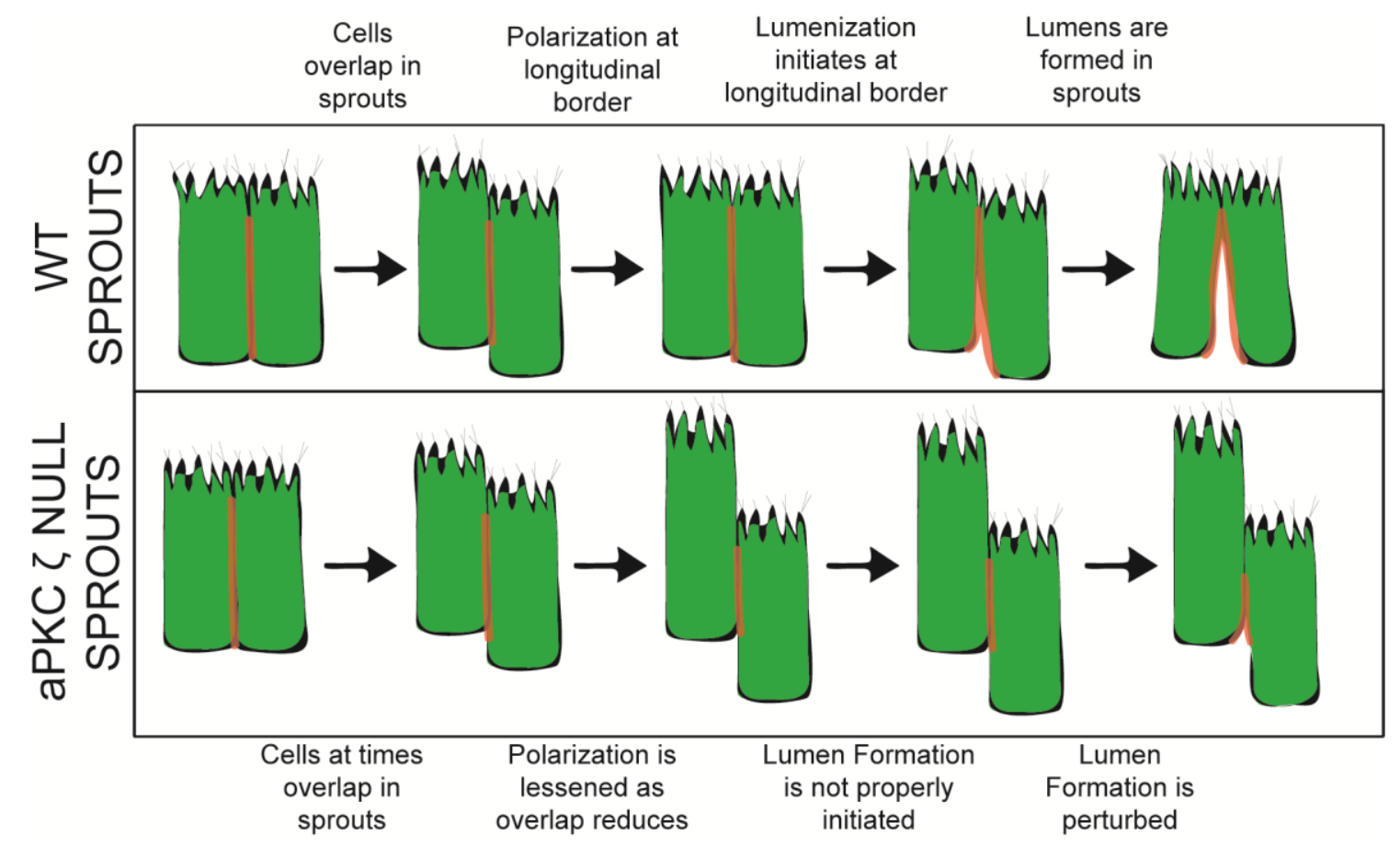




\section{REFERENCES}

Akimoto K, Mizuno K, Osada S, Hirai S, Tanuma S, et al. 1994. A new member of the third class in the protein kinase $\mathrm{C}$ family, PKC lambda, expressed dominantly in an undifferentiated mouse embryonal carcinoma cell line and also in many tissues and cells. The Journal of biological chemistry 269: 12677-83

Arima S, Nishiyama K, Ko T, Arima Y, Hakozaki Y, et al. 2011. Angiogenic morphogenesis driven by dynamic and heterogeneous collective endothelial cell movement. Development 138: 4763-76

Blum Y, Belting HG, Ellertsdottir E, Herwig L, Luders F, Affolter M. 2008. Complex cell rearrangements during intersegmental vessel sprouting and vessel fusion in the zebrafish embryo. Developmental biology 316: 312-22

Bryant DM, Datta A, Rodriguez-Fraticelli AE, Peranen J, Martin-Belmonte F, Mostov KE. 2010. A molecular network for de novo generation of the apical surface and lumen. Nature cell biology 12: 1035-45

Flamme I, Baranowski A, Risau W. 1993. A new model of vasculogenesis and angiogenesis in vitro as compared with vascular growth in the avian area vasculosa. The Anatomical record 237: 49-57

Gerhardt H, Golding M, Fruttiger M, Ruhrberg C, Lundkvist A, et al. 2003. VEGF guides angiogenic sprouting utilizing endothelial tip cell filopodia. The Journal of cell biology 161: 1163-77

Herwig L, Blum Y, Krudewig A, Ellertsdottir E, Lenard A, et al. 2011. Distinct cellular mechanisms of blood vessel fusion in the zebrafish embryo. Current biology: $C B$ 21: $1942-8$

Horikoshi Y, Suzuki A, Yamanaka T, Sasaki K, Mizuno K, et al. 2009. Interaction between PAR-3 and the aPKC-PAR-6 complex is indispensable for apical domain development of epithelial cells. Journal of cell science 122: 1595-606

Horne-Badovinac S, Lin D, Waldron S, Schwarz M, Mbamalu G, et al. 2001. Positional cloning of heart and soul reveals multiple roles for PKC lambda in zebrafish organogenesis. Current biology : CB 11: 1492-502

Horvat R, Hovorka A, Dekan G, Poczewski H, Kerjaschki D. 1986. Endothelial cell membranes contain podocalyxin--the major sialoprotein of visceral glomerular epithelial cells. The Journal of cell biology 102: 484-91

Jakobsson L, Franco CA, Bentley K, Collins RT, Ponsioen B, et al. 2010. Endothelial cells dynamically compete for the tip cell position during angiogenic sprouting.

Nature cell biology 12: 943-53 
Kamei M, Saunders WB, Bayless KJ, Dye L, Davis GE, Weinstein BM. 2006. Endothelial tubes assemble from intracellular vacuoles in vivo. Nature 442: 453-6

Koh W, Mahan RD, Davis GE. 2008. Cdc42- and Rac1-mediated endothelial lumen formation requires Pak2, Pak4 and Par3, and PKC-dependent signaling. Journal of cell science 121: 989-1001

Lee CY, Bautch VL. 2011. Ups and downs of guided vessel sprouting: the role of polarity. Physiology (Bethesda) 26: 326-33

Leitges M, Sanz L, Martin P, Duran A, Braun U, et al. 2001. Targeted disruption of the zetaPKC gene results in the impairment of the NF-kappaB pathway. Molecular cell 8: 771-80

Lizama CO, Zovein AC. 2013. Polarizing pathways: balancing endothelial polarity, permeability, and lumen formation. Experimental cell research 319: 1247-54

Nakatsu MN, Davis J, Hughes CC. 2007. Optimized fibrin gel bead assay for the study of angiogenesis. Journal of visualized experiments : JoVE: 186

Nakayama M, Nakayama A, van Lessen M, Yamamoto H, Hoffmann S, et al. 2013. Spatial regulation of VEGF receptor endocytosis in angiogenesis. Nature cell biology 15: 249-60

Ohno S. 2001. Intercellular junctions and cellular polarity: the PAR-aPKC complex, a conserved core cassette playing fundamental roles in cell polarity. Current opinion in cell biology 13: 641-8

Ono Y, Fujii T, Ogita K, Kikkawa U, Igarashi K, Nishizuka Y. 1988. The structure, expression, and properties of additional members of the protein kinase $\mathrm{C}$ family. The Journal of biological chemistry 263: 6927-32

Risau W. 1997. Mechanisms of angiogenesis. Nature 386: 671-4

Ruzankina Y, Pinzon-Guzman C, Asare A, Ong T, Pontano L, et al. 2007. Deletion of the developmentally essential gene ATR in adult mice leads to age-related phenotypes and stem cell loss. Cell stem cell 1: 113-26

Selbie LA, Schmitz-Peiffer C, Sheng Y, Biden TJ. 1993. Molecular cloning and characterization of $\mathrm{PKC}$ iota, an atypical isoform of protein kinase $\mathrm{C}$ derived from insulin-secreting cells. The Journal of biological chemistry 268: 24296-302

Siekmann AF, Affolter M, Belting HG. 2013. The tip cell concept 10 years after: new players tune in for a common theme. Experimental cell research 319: 1255-63 
Stahl A, Connor KM, Sapieha P, Chen J, Dennison RJ, et al. 2010. The mouse retina as an angiogenesis model. Investigative ophthalmology \& visual science 51: 2813-26

Strilic B, Kucera T, Eglinger J, Hughes MR, McNagny KM, et al. 2009. The molecular basis of vascular lumen formation in the developing mouse aorta. Developmental cell 17: $505-15$

Whyte J, Thornton L, McNally S, McCarthy S, Lanigan F, et al. 2010. PKCzeta regulates cell polarisation and proliferation restriction during mammary acinus formation. Journal of cell science 123: 3316-28

Wodarz A, Ramrath A, Grimm A, Knust E. 2000. Drosophila atypical protein kinase C associates with Bazooka and controls polarity of epithelia and neuroblasts. The Journal of cell biology 150: 1361-74

Zovein AC, Luque A, Turlo KA, Hofmann JJ, Yee KM, et al. 2010. Beta1 integrin establishes endothelial cell polarity and arteriolar lumen formation via a Par3dependent mechanism. Developmental cell 18: 39-51 


\section{Chapter IV- General Discussion}

Blood vessels are a polarized, lumenized tissue. Apical-basal polarity is needed to properly form the vascular network. Despite this, our understanding of how apical-basal polarity is established is limited. Therefore, the original goal in this project was to determine if polarity is established in sprouts and if so where polarity establishes. The current model in the field suggested that one single tip cell led the sprout, with stalk cells behind it (Hellstrom et al 2007). Because of this, I hypothesized that apical-basal polarity is established at the cell-cell border between two stalk cells. Surprisingly, I discovered that the leading cell in a sprout, or tip cell, is overlapped by a secondary leading/tip cell. This alters the canonical model used in the field and creates a longitudinal cell-cell border between the leading two cells. Because of this, apical-basal polarity is able to establish and does establish at the border between these cells. Lumen formation is dependent on podocalyxin (Strilic et al 2010), which is seen localizing to the longitudinal cell-cell border. I found lumen formation occurs at the cell-cell border between overlapping tip cells. These findings contradict the single tip cell model, adding novel insight into the mechanism by which developing blood vessels become lumenized.

Previous work on signaling within sprouts has been interpreted in the context of the single tip cell model. The two-tip cell model is compatible with these signaling mechanisms, but will alter the way the field conceptualizes multiple signaling pathways involved in sprouting. For example, Notch signaling plays a role in 
establishing tip cell versus stalk cell fate (Hellstrom et al 2007). Decreasing Notch signaling through a $\mathrm{Y}$-secretase inhibitor, genetic inactivation of one allele of the ligand, dll4, or through genetic deletion of the Notch receptor all result in an increased number of sprouts (Hellstrom et al 2007). The inverse experiment, increasing Notch signaling with the ligand jagged1, reduces the number of sprouts at the vascular front, demonstrating that Notch signaling promotes the tip cell fate (Hellstrom et al 2007). This data, in conjunction with Notch activity in sprouts, led to a model in which a single tip cell laterally inhibits tip cell fate in the neighboring stalk cells (Jakobsson et al 2010). While the role of Notch signaling in determining tip cell fate led to the assumption of a single tip cell, Notch lateral inhibition is not incompatible with a two tip cell model. Interestingly, Hes6, in Drosophila, and myt1 in chick and mouse pancreatic cells have been shown to dampen the effects of Notch signaling (Ahnfelt-Ronne et al 2007, Bae et al 2000, Wang et al 2007), thus it may be possible that one tip cell expresses Notch to laterally inhibit tip cell fate in the stalk cells, while the second tip cell is immune to lateral inhibition. Future studies will be needed to determine how Notch signaling is functioning in this complex cellular arrangement. For example, experiments immunostaining DII4 within mosaic sprouts will demonstrate whether there is heterogeneous expression between overlapping tip cells or if the overlapping cells have similar levels of DII4. Additional studies looking at tip cell overlap in Notch mutant cell lines will determine if Notch signaling promotes overlap or inhibits cellular overlap at the tip of sprouts.

The two-tip cell topology also raises the question of how two tip cells can cooperate to interpret external stimulus and migrate along the vascular endothelial 
growth factor (VEGF) gradient. In the single tip cell model, the tip cell is the only cell extending filopodia and sensing the VEGF gradient (Chappell et al 2009, Gerhardt et al 2003). The two tip cell model implies two different cells receive incoming information to the sprout, and the two cells must interpret that signaling. This is another reason research discerning the way Notch signaling works is important. Further research will determine the signaling dynamics of two tip cells, including if Notch lateral inhibition prevents one of the cells from sensing the VEGF gradient, and will elucidate whether this affects the sprout's path of migration.

Though little was known about the cellular topology within sprouts as I started my project, two papers came out shortly after this project started showing that tip cells do not remain at the front indefinitely, but switch place with stalk cells over time (Arima et al 2011, Jakobsson et al 2010). Prior to these findings, I hypothesized that the cells in the sprout would remain statically positioned relative to one another. In opposition to this idea, these papers demonstrated that tip cells switch places and that endothelial cells dynamically move within the sprout (Arima et al 2011, Jakobsson et al 2010). My data supported their findings, showing that based on nuclei position, cells switch place every 5.5 hours in the sprouting angiogenesis assay. Based on these results, endothelial cells must overlap, for at least as long as they are switching. Despite this, these papers and the field retained the single tip cell model. These papers likely ignored the overlap because of their methods. They measured the position of the cell based on the position of the cell nucleus in fixed in vivo assays and live imaging of in vitro assays (Arima et al 2011, Jakobsson et al 2010). My work analyzed cell positioning based on the location of cell cytoplasm, 
and I was able to demonstrate that overlap is maintained during switching and that the movement of the leading edge of the cells does not correlate with the nuclear movement on a small time scale. The movement of the leading edge is dynamic, moving both forward and backward. This suggests that the movement of the leading edge of the cells is helping to maintain the close proximity of the leading edge, which would maintain cellular overlap. The studies on tip cell competition set the foundation for my work, but they drastically underestimated the prevalence of the two-tip cell topology.

In the mouse aorta, endothelial cells establish an apical domain at the cell-cell membrane between two cells, (Strilic et al 2009), and therefore, I hypothesized that sprouts would use a similar method to establish an apical domain along a longitudinal border between stalk cells. My discovery of tip cell overlap led me to alter my hypothesis, now predicting that the apical domain would be established between the leading two cells. Indeed, I discovered that cells establish the apical domain at the longitudinal border between tip cells.

Lumenization is a necessary process for forming a proper vascular network (Lammert \& Axnick 2012). At the onset of this project, there were two competing models for lumen formation: cell hollowing and cord hollowing (Blum et al 2008, Kamei et al 2006, Koh et al 2008, Strilic et al 2009). Although cell hollowing was initially proposed as the mechanism for lumen formation in zebrafish blood vessels, recent literature showed that cells were overlapped in intersegmental vessels at the site of lumen formation, disproving previous work supporting intracellular lumen formation in the zebrafish intersegmental vessels (Blum et al 2008, Kamei et al 
2006). Furthermore, the mouse aorta lumen forms between multiple cells (Strilic et al 2009), suggesting that cord hollowing may also be the mechanism for lumen formation in mice. Because of these studies I hypothesized that lumen formation in angiogenesis occurred through a cord hollowing mechanism, forming between multiple cells. Supporting this hypothesis, I discovered that patent lumens exist between two cells in sprouts. One potential benefit of having two overlapping cells at the front of a sprout is that the overlap allows polarization and lumenization to occur and occur distally, closer to the front, within sprouts. This would potentially allows blood to reach the surrounding tissues as quickly as possible. Two tip cells with a lumen between them may also facilitate anastomosis, the process of sprouts connecting with another sprout or vessel. Blood vessels utilize overlapping cells after anastomosis to create a lumen (Blum et al 2008). My work suggests that lumen formation in angiogenesis occurs via a cord hollowing mechanism.

To determine the molecular mechanism for establishing or maintaining this cellular topology, polarization or lumenization, I examined pathways already known to regulate polarity. $\mathrm{aPKC} \zeta$ emerged as a candidate because of its large number of roles in polarization and lumenization (Ohno 2001) in epithelia, and I hypothesized that aPKC $\zeta$ would be necessary for proper cell polarization in sprouts. Consistent with this hypothesis, we observed that $\mathrm{aPKC} \zeta$ null mice have less cellular overlap and therefore the formation of the apical domain and lumenization do not occur as distally in sprouts. How aPKC might work is this system is currently unknown, but is reasonable to speculate that it might have a role similar to that observed in epithelia/small animal models. In the canonical pathway, aPKC $\zeta$ phosphorylates, 
and thereby inhibits glycogen synthase kinase 3 beta (GSK-3ß), a kinase known to inhibit the protein adenomatous polyposis coli (APC) (Rubinfeld et al 1996). This pathway polarizes the microtubule organizing center (MTOC), thereby regulating the polarized cellular migration (Etienne-Manneville \& Hall 2003). One possible mechanism of reduced overlap in $\mathrm{aPKC} \zeta$ knockout is that $\mathrm{aPKC} \zeta$ could facilitate the polarization of the cells in the direction of migration, thereby affecting the ability of endothelial cells to properly migrate in the proper direction within the sprout. aPKC $\zeta$ loss could prevent proper migration through loss of localized stabilization of microtubules (Etienne-Manneville \& Hall 2003). Alternatively, aPKC $\zeta$ could function at the apical domain to maintain the cellular overlap, by affecting the cell-cell adhesions in sprouts. aPKC is necessary for the maturation of the adherens junction (AJ) allowing the transition from spot like $A J$ to the mature belt $A J$, and loss of aPKC in Drosophila shows a loss of proper epithelial cell shape and organization in gastrulation (Harris \& Peifer 2007). A perturbation in proper junction stabilization and maturity may prevent the needed adhesion to maintain overlap between two cells prior to lumen formation. This explanation would also help establish how cellular overlap would be maintained within the context of Notch signaling, because if overlap is maintaining through adhesion, then Notch lateral inhibition would not prevent cellular overlap. Future studies will be needed to determine the mechanism in which aPKC $\zeta$ maintain cellular overlap within sprouts. Isolation of aPKC $\zeta$ null endothelial cells would allow the study of the affects of aPKC $\zeta$ knock down on cell dynamics. These experiments would determine whether aPKC $\zeta$ null sprouts have altered cell migration. In addition, Katie Bentley has developed quantitative anaylsis 
of VE-Cadherin to determine junction strength between cells (Bentley et al 2014).

This would allow determination of whether junctional stability between cells is perturbed in the knock out situation.

My work into the polarization of angiogenic sprouts will allow further studies of polarization within vascular biology. One of the potential implications of my findings include applications within therapeutic drugs used by cancer patients. Tumors recruit blood vessels to help supply the growing tumor with oxygen and nutrients. Tumor induced vessels are fenestrated, with improper intercellular adhesion (Roberts \& Palade 1997). These leaky blood vessels cause impaired drug delivery and may lead to the increased cancer metastasis (Jain 1988, Sullivan \& Graham 2007). The underlying causes of this defect remain unclear, and polarization defects remain one possible cause. Improper establishment of the apical domain could lead to improper adhesion between endothelial cells and therefore create fenestrated vessels. Treatment to reverse this leakiness could allow better drug delivery and reduce invasiveness, therefore understanding its root causes can lead to breakthroughs in drug development, and the initial polarization is a possible root cause.

In conclusion, while analyzing polarization of angiogenic sprouts I discovered a novel cellular topology in angiogenic sprouts, altering the current working model in the field. The longitudinal cell-cell border allows the tip cells to establish apical-basal polarity, and form a lumen. This gives new insight into the polarization of angiogenic sprouts, and adds support to the cord hollowing mechanism of lumen formation. I 
discovered that $\mathrm{aPKC} \zeta$ is necessary for the proper cellular arrangement in sprouts, and then demonstrated that polarization and lumen formation are perturbed. 


\section{REFERENCES}

Ahnfelt-Ronne J, Hald J, Bodker A, Yassin H, Serup P, Hecksher-Sorensen J. 2007. Preservation of proliferating pancreatic progenitor cells by Delta-Notch signaling in the embryonic chicken pancreas. BMC developmental biology 7: 63

Arima S, Nishiyama K, Ko T, Arima Y, Hakozaki Y, et al. 2011. Angiogenic morphogenesis driven by dynamic and heterogeneous collective endothelial cell movement. Development 138: 4763-76

Bae S, Bessho Y, Hojo M, Kageyama R. 2000. The bHLH gene Hes6, an inhibitor of Hes1, promotes neuronal differentiation. Development 127: 2933-43

Blum Y, Belting HG, Ellertsdottir E, Herwig L, Luders F, Affolter M. 2008. Complex cell rearrangements during intersegmental vessel sprouting and vessel fusion in the zebrafish embryo. Developmental biology 316: 312-22

Chappell JC, Taylor SM, Ferrara N, Bautch VL. 2009. Local guidance of emerging vessel sprouts requires soluble Flt-1. Developmental cell 17: 377-86

Etienne-Manneville S, Hall A. 2003. Cdc42 regulates GSK-3beta and adenomatous polyposis coli to control cell polarity. Nature 421: 753-6

Gerhardt H, Golding M, Fruttiger M, Ruhrberg C, Lundkvist A, et al. 2003. VEGF guides angiogenic sprouting utilizing endothelial tip cell filopodia. The Journal of cell biology 161: 1163-77

Harris T], Peifer M. 2007. aPKC controls microtubule organization to balance adherens junction symmetry and planar polarity during development. Developmental cell 12: $727-38$

Hellstrom M, Phng LK, Hofmann JJ, Wallgard E, Coultas L, et al. 2007. Dll4 signalling through Notch1 regulates formation of tip cells during angiogenesis. Nature 445: 776-80

Jain RK. 1988. Determinants of tumor blood flow: a review. Cancer research 48: 2641-58

Jakobsson L, Franco CA, Bentley K, Collins RT, Ponsioen B, et al. 2010. Endothelial cells dynamically compete for the tip cell position during angiogenic sprouting. Nature cell biology 12: 943-53

Kamei M, Saunders WB, Bayless KJ, Dye L, Davis GE, Weinstein BM. 2006. Endothelial tubes assemble from intracellular vacuoles in vivo. Nature 442: 453-6 
Koh W, Mahan RD, Davis GE. 2008. Cdc42- and Rac1-mediated endothelial lumen formation requires Pak2, Pak4 and Par3, and PKC-dependent signaling. Journal of cell science 121: 989-1001

Lammert E, Axnick J. 2012. Vascular lumen formation. Cold Spring Harbor perspectives in medicine 2: a006619

Ohno S. 2001. Intercellular junctions and cellular polarity: the PAR-aPKC complex, a conserved core cassette playing fundamental roles in cell polarity. Current opinion in cell biology 13: 641-8

Roberts WG, Palade GE. 1997. Neovasculature induced by vascular endothelial growth factor is fenestrated. Cancer research 57: 765-72

Rubinfeld B, Albert I, Porfiri E, Fiol C, Munemitsu S, Polakis P. 1996. Binding of GSK3beta to the APC-beta-catenin complex and regulation of complex assembly. Science 272: 1023-6

Strilic B, Eglinger J, Krieg M, Zeeb M, Axnick J, et al. 2010. Electrostatic cell-surface repulsion initiates lumen formation in developing blood vessels. Current biology : CB 20: 2003-9

Strilic B, Kucera T, Eglinger J, Hughes MR, McNagny KM, et al. 2009. The molecular basis of vascular lumen formation in the developing mouse aorta. Developmental cell 17: $505-15$

Sullivan R, Graham CH. 2007. Hypoxia-driven selection of the metastatic phenotype. Cancer metastasis reviews 26: 319-31

Suzuki A, Ishiyama C, Hashiba K, Shimizu M, Ebnet K, Ohno S. 2002. aPKC kinase activity is required for the asymmetric differentiation of the premature junctional complex during epithelial cell polarization. Journal of cell science 115: 3565-73

Wang S, Zhang J, Zhao A, Hipkens S, Magnuson MA, Gu G. 2007. Loss of Myt1 function partially compromises endocrine islet cell differentiation and pancreatic physiological function in the mouse. Mechanisms of development 124: 898-910 